\title{
Work-Related Health Disorders among Saudi Computer Users
}

\author{
Ibrahim M. Jomoah \\ Department of Industrial Engineering, Faculty of Engineering, King Abdulaziz University (KAU), P.O. Box 80204, \\ Jeddah 21589, Saudi Arabia \\ Correspondence should be addressed to Ibrahim M. Jomoah; ijomoah@kau.edu.sa
}

Received 26 January 2014; Revised 9 July 2014; Accepted 7 August 2014; Published 14 October 2014

Academic Editor: Pasquale Aragona

Copyright (C) 2014 Ibrahim M. Jomoah. This is an open access article distributed under the Creative Commons Attribution License, which permits unrestricted use, distribution, and reproduction in any medium, provided the original work is properly cited.

\begin{abstract}
The present study was conducted to investigate the prevalence of musculoskeletal disorders and eye and vision complaints among the computer users of King Abdulaziz University (KAU), Saudi Arabian Airlines (SAUDIA), and Saudi Telecom Company (STC). Stratified random samples of the work stations and operators at each of the studied institutions were selected and the ergonomics of the work stations were assessed and the operators' health complaints were investigated. The average ergonomic score of the studied work station at STC, KAU, and SAUDIA was $81.5 \%, 73.3 \%$, and 70.3, respectively. Most of the examined operators use computers daily for $\leq 7$ hours, yet they had some average incidences of general complaints (e.g., headache, body fatigue, and lack of concentration) and relatively high level of incidences of eye and vision complaints and musculoskeletal complaints. The incidences of the complaints have been found to increase with the (a) decrease in work station ergonomic score, (b) progress of age and duration of employment, (c) smoking, (d) use of computers, (e) lack of work satisfaction, and (f) history of operators' previous ailments. It has been recommended to improve the ergonomics of the work stations, set up training programs, and conduct preplacement and periodical examinations for operators.
\end{abstract}

\section{Introduction}

The one thing that has had the greatest impact on our lives in modern time is the computer. Along with smaller size and affordable prices, there has been the advent of the Internet. This has ensured that people use this technology either at their work place or at home. Meanwhile, the applications of computer technology and the accompanying use of video display terminals (VDTs) are revolutionizing the workplaces worldwide, and their use will continue to grow in the future.

Although these developments may perform operators' tasks efficiently, they could face some factors such as work stress, repetitious tasks, boredom, interpersonal factors, unsafe postures, and poor design of workstation that will negatively affect their health, performance, and productivity. For example, the development of VDTs technology may have contributed to the increase of users' health problems such as cumulative trauma disorders (CTDs) of upper extremity and back pain [1-54] as well as vision problems $[1-11,13,14,19,20$, $26,44,45,51-53,55-84]$.

However, the application of ergonomics principles to office workstations will reduce such health risks. For example, one of the goals of the ergonomic processes is to design or modify people's work and other activities to be within their capabilities and limitations $[3,5-7,12,15-17,22,23$, $28-30,38,44-46,85-88]$. One possible outcome of poor harmonization is disorder of the musculoskeletal system known as repetitive strain injuries (RSI), CTD, or activity and work-related musculoskeletal disorder (WMSD). Those working in office-type jobs involving keyboarding and other computer related activities suffer from these disorders $[9,13$, $15-18,22-24,28,33,42,50,88]$.

Currently computer related injuries are developing into an epidemic among computer users. It is estimated that, worldwide, $25 \%$ of computer users are already suffering from computer related injuries [35]. The United States has to shell out more than 2 billion US dollars annually for having ignored these computer related problems. It is now proved that the duration of work and computer-related problems are positively correlated. It is not uncommon these days for people having to leave computer dependent careers or even be permanently disabled and unable to perform tasks such as driving or dressing themselves. Occupationally caused RSI rank first among the health problems potentially affecting 
the quality of life [89]. Meanwhile, poor workstation design and poor ergonomics have been associated with an increased risk of developing these disorders.

The tremendous use of computer by the staff members, technicians, and students at King Abdulaziz University (KAU), by our experience, has been accompanied by increase in the number of attendances to University Medical Directorate (Services) with general, eye and vision, and musculoskeletal complaints. When this observation was brought to the attention of KAU officials, they urged and encouraged concerned personnel to study the nature of this problem and propose remedial actions.

Meanwhile, one of the first institutions that had applied computer technology in Saudi Arabia was the Saudi Airlines tickets' reservation offices (SAUDIA). It is considered to be one of most eligible areas to conduct a study regarding VDT health related problems. Putting this in mind, KAU urged concerned personnel to include it in the present study. Also, the Saudi Telecom Company (STC) works in Jeddah comprises nearly 430 VDT workstations where 360 operators and mostly 70 supervisors work for whole shifts. There have been some claims that these operators and supervisors suffer some general musculoskeletal and eye and vision complaints. Consequently, these works have been decided to be included in this study.

The objectives of the present study were

(1) to evaluate the magnitude of the problem of inconveniences in the use of computers in KAU, SAUDIA, and STC, as well as the inconveniences in the computers' workstations,

(2) to investigate computers' operators health complaints,

(3) to investigate environmental and behavioral factors contributing to the occurrence of the complaints,

(4) to propose remedial actions that might contribute to reducing these complaints.

\section{Methodology}

2.1. Study Population. Inventories of the computer workstations and operators in the different colleges and units of KAU, in the different departments and units of SAUDIA tickets' reservation offices, and in the different departments and units of STC head office in Jeddah had, primarily, been conducted to assess the magnitude of computer use there. The findings of the inventories are summarized in Table 1.

Representative random samples of 100 workstations, and operators (all males, since no females are employed there), were selected from each of the three institutions, considering that the selection of the sampled stations and operators had been affected by the readiness of the individual administrations and operators in the different departments and units to participate in the study. The selected stations are also presented in Table 1.

2.2. Studying Ergonomics of Workstations. A study form entitled "Ergonomics Rating of Computer Applications" was developed to assess the ergonomics status of the studied computer workstations. The form was designed after reviewing the ANS/HFES Committee document [6], and many computer's workstation evaluation checklists that had been tested and used by international institutions include

(1) U.S. Department of Health and Human Services, Centers of Disease Control, and Prevention (CDC), Evaluation Checklist;

(2) National Institute for Occupation Safety and Health (NIOSH) Ergonomics Work-Place Evaluations of Musculoskeletal Disorders Checklist;

(3) U.S. Department of Labor, Occupational Safety, and Health Agency (OSHA) Computer Workstation Ergonomic Checklist;

(4) University of California Computer Workstation SelfEvaluation Checklist;

(5) California State University Ergonomics Evaluation Checklist;

(6) Cornell University Ergonomics Checklist;

(7) University of Virginia Library Ergonomics Evaluation Form;

(8) Institute for Occupational Physiology at the University of Dortmund Checklist for Computer Workstation;

(9) Atlantic Mutual Centennial Insurance Company Workstation Checklist.

The ergonomics score for the evaluation of the workstation is 43 , distributed by the different components. Each component has certain number of scores, determining the maximum score of the component as shown in Table 2. Besides, 3 scores are allowed for the work organization and 4 scores for the training and provision of information, making a total score for the work at the specific workstation of 50, which is equivalent to $100 \%$ when scoring percentagewise.

Each score item is clearly presented to be answered by "Yes" or "No" to avoid any personal differences or any bias by the evaluators. The "Yes" answers are counted to represent the score out of 50 , and some ten stations were evaluated to test the study from and found to be satisfactory for the conduct of the study. Furthermore, the evaluation of the workstations was carried out, only, by the authors for quality assurance of the data collection. The study form has been designed in four major sections including the following.

Section (1). It includes basic information of investigated organizations (colleges/units), particularly as related to presented services.

Section (2). It includes ergonomics rating of investigated workstations by checking the details of each component of the work place, including

(1) desk, as related to space of desk top, layout of the desk, top equipment, desk top and distance from operator's eye, and existence of comfortable resting facility for operators' hands and rest; 
TABLE 1: Existing computer workstations and operators in the different units of KAU, SAUDIA, and STC and the sample selected for the study.

\begin{tabular}{|c|c|c|c|c|c|c|c|}
\hline \multirow{2}{*}{ Institution } & \multirow{2}{*}{ Units } & \multicolumn{3}{|c|}{ Existing service } & \multicolumn{3}{|c|}{ Sample } \\
\hline & & Workstation & Supervisor & Operator & Workstation & Supervisor & Operator \\
\hline \multirow{13}{*}{$\begin{array}{l}\text { King } \\
\text { Abdulaziz } \\
\text { University } \\
\text { (KAU) }\end{array}$} & $\begin{array}{l}\text { (i) Higher administration, } \\
\text { including } \\
\text { Deanship of Admission and } \\
\text { Registration and Deanship of } \\
\text { Student Affairs }\end{array}$ & 301 & & & 14 & & \\
\hline & $\begin{array}{l}\text { (ii) Deanship of Information } \\
\text { Technology }\end{array}$ & 114 & & & 16 & & \\
\hline & (iii) Deanship of Library Affairs & 73 & & & & & \\
\hline & $\begin{array}{l}\text { (iv) Faculty of Economics and } \\
\text { Administration }\end{array}$ & 96 & & & 9 & & \\
\hline & (v) Faculty of Sciences & 86 & & & 9 & & \\
\hline & (vi) Faculty of Engineering & 130 & & & 16 & & \\
\hline & $\begin{array}{l}\text { (vii) Faculty of Medicine and } \\
\text { University Hospital }\end{array}$ & 34 & & & 17 & & \\
\hline & $\begin{array}{l}\text { (viii) Faculty of Arts and } \\
\text { Humanities }\end{array}$ & 81 & & & 14 & & \\
\hline & (ix) Faculty of Earth Sciences & 63 & & & 5 & & \\
\hline & $\begin{array}{l}\text { (x) Faculty of Environmental } \\
\text { Designs }\end{array}$ & 41 & & & & & \\
\hline & (xi) Faculty of Marine Sciences & 8 & & & & & \\
\hline & $\begin{array}{l}\text { (xii) Faculty of Meteorology, } \\
\text { Environment and Arid Land } \\
\text { Agriculture }\end{array}$ & 16 & & & & & \\
\hline & Total & 1043 & & & 100 & & \\
\hline \multirow{6}{*}{$\begin{array}{l}\text { Saudi Airlines } \\
\text { Ticket } \\
\text { Reservation } \\
\text { (SAUDIA) }\end{array}$} & $\begin{array}{l}\text { (i) Central Control for Africa and } \\
\text { Europe Flights }\end{array}$ & 20 & & & 15 & & \\
\hline & $\begin{array}{l}\text { (ii) Central Control for Local and } \\
\text { Gulf Flights }\end{array}$ & 20 & & & 15 & & \\
\hline & $\begin{array}{l}\text { (iii) Central Control for Asia and } \\
\text { Middle East Flights }\end{array}$ & 10 & & & 5 & & \\
\hline & $\begin{array}{l}\text { (iv) Record and Follow-up } \\
\text { Department }\end{array}$ & 20 & & & 10 & & \\
\hline & $\begin{array}{l}\text { (v) Customer Services } \\
\text { Department }\end{array}$ & 165 & & & 55 & & \\
\hline & Total & 235 & & & 100 & & \\
\hline \multirow{4}{*}{$\begin{array}{l}\text { Saudi Telecom } \\
\text { Company } \\
\text { (STC) }\end{array}$} & $\begin{array}{l}\text { (i) English Call Services } \\
\text { Department }\end{array}$ & & 15 & 90 & & 4 & 16 \\
\hline & (ii) Help Services Department & & 24 & 120 & & 8 & 27 \\
\hline & (iii) Other Services Department & & 30 & 150 & & 10 & 35 \\
\hline & Total & & 69 & 360 & & 22 & 78 \\
\hline
\end{tabular}

(2) seat, as related to dimensions, casters, operators' leg clearance, armrests, back rest, seat cushion, and seat comfort ability and stability;

(3) footrest, as related to need, availability, and status of footrest;

(4) display screen, as related to location, height and tilting of the monitor, distance from operator's eye, freedom of screen from glare and reflection, stability of image and freedom from flickering, ease to read characters, and possibility of adjusting screen brightness and contrast;
(5) keyboard, as related to dimensions, location with reference to operator's hands and elbows, and exchanging operation between keyboard and mouse without operator's hand extension or twisting wrist;

(6) mouse, as related to its location with reference to operator smooth running and operator's awareness of its details of operation and maintenance;

(7) document holder, as related to need, availability, and status of the document holder; 
TABLE 2: Distribution of the ergonomics scores of the different components of the studied workstations.

\begin{tabular}{lc}
\hline Workstation component & Maximum score \\
\hline (1) Desk & 5 \\
(2) Seat & 6 \\
(3) Footrest & 1 \\
(4) Display screen & 8 \\
(5) Keyboard & 3 \\
(6) Mouse & 3 \\
(7) Document holder & 2 \\
(8) Space and room layout & 7 \\
(9) Task and posture & 2 \\
(10) Illumination & 4 \\
(11) Noise and thermal environment & 2 \\
\hline Total scores & 43 \\
\hline
\end{tabular}

(8) space and room layout, as related to adequate access to work place, availability of space to maneuver the seat, work correct posture, availability of adequate space for equipment needed for work, location of monitor with reference to windows, freedom of work area from obstructions, and hazards of tripping and neatness of the work area;

(9) task and posture, as related to freedom of operator's hands from phone while typing and resting his hand wrists;

(10) illumination, as related to level of lighting, status of luminaries and illumination fixtures, use of blinds on windows, and background of the screen with surrounding environment;

(11) noise and thermal environment, as related to level of quietness and status of air conditioning in work area.

Section (3). It includes work organization rating, by investigating work organization, work hours, rest pauses and noncomputer work assignment, and work load.

Section (4). It includes training and provision of information, by investigating operator's on-the-job and formal training, certainty of his use of software, keying habits, operator's capability of control of his workstation and work environment, and operator's adoption of good posture and avoiding visual fatigue at work.

2.3. Investigating Operators' Health Symptoms. A study form entitled "Impact of Computer Use on Operators" was developed to evaluate the effect of computer use on operator's health as reviewed and/or recommended by the NIOSH [1],
WHO [5], and ANSI/HFES [6]. It is divided into four main sections as follows.

Section (1). It includes basic data, including name, gender, address, workstation, age, education, and smoking habit.

Section (2). It includes work data, including work type, duration of employment, formal training, work speed, daily hours of computer use, nature of computer use (continuous or intermittent), and work satisfaction.

Section (3). It includes health disorders before present work, including previous ailments or complaints of the musculoskeletal system and complaints of the eye and vision.

Section (4). It includes current symptoms, including the general complaints and their frequency, the eye and vision symptoms and their frequency, the maximum work hours before their occurrence and the time required for their release, and the musculoskeletal disorders and their location, description, frequency, and persistence, as well as the approached medical treatment and the sickness absenteeism as related to the work-related ailments.

2.4. Data Analysis. The collected data were visually inspected for fliers, then introduced into PC, and subjected to statistical analysis using Microsoft Excel 2007.

\section{Results and Discussion}

3.1. Ergonomics of the Workstations. The ergonomics scores of the studied workstations in the three institutions are illustrated in Table 3 and Figures 1 and 2. The average workstations score in STC has been rated very good (81.5 \pm 14.34) which is considerably higher than the scores of both KAU and SAUDIA $(73.3+15.13$ and $70.3 \pm 13.54$, resp.) (Figure 2). This might be attributed to the relatively recent establishment of the workstations in STC in comparison to the other two study locations (KAU and SAUDIA). However, the score of the different components varies considerably in the three locations. For example, task and posture has been rated $95 \%$ and $90 \%$ at STC and SAUDIA, respectively, while it has been the lowest scored component at KAU (54\%). Also, work organization has been rated the second highest (98.3\%) at SAUDIA while it has been rated the second lowest at KAU (57.7\%) and in the middle of the scores at SAUDIA (73.2\%). These variations might be attributed to the differences of the type of work and pattern of computer use at the different study locations. The distribution of the ergonomics scores of the examined workstations might be considered to follow normal model but truncated (Figure 2).

3.2. Characteristics of the Work Population. The demographic and occupational characteristics of the studied populations of the computer users/operators in the three institutions are presented in Tables 4 and 5. The populations at the different study locations were mostly young, since $98 \%$ of the subjects in both KAU and STC, and $89 \%$ at SAUDIA, were younger than 50 years. However, the subjects of the study population 
TABLE 3: Positive ergonomics components of the examined workstations.

\begin{tabular}{|c|c|c|c|c|c|c|c|}
\hline \multirow{2}{*}{\multicolumn{2}{|c|}{ NumberErgonomics components }} & \multicolumn{2}{|l|}{$\operatorname{KAU}^{*}(N=100)$} & \multicolumn{2}{|c|}{ SAUDIA $^{* *}(N=100)$} & \multicolumn{2}{|c|}{$\operatorname{STC}^{* * *}(N=100)$} \\
\hline & & Number of positives & Average & Number of positives & Average & Number of positives & Average \\
\hline I & Noise and thermal environment & & & & & & \\
\hline 1 & Quietness & 75 & \multirow{2}{*}{84.0} & 78 & \multirow{2}{*}{81.5} & 83 & \multirow{2}{*}{86.5} \\
\hline 2 & Air-conditioning & 93 & & 85 & & 90 & \\
\hline II & Display screen & & & & & & \\
\hline 3 & Monitor location & 71 & \multirow{8}{*}{80.4} & 70 & \multirow{8}{*}{75.4} & 97 & \multirow{8}{*}{87.4} \\
\hline 4 & Monitor top & 80 & & 100 & & 99 & \\
\hline 5 & Monitor distance from eye & 71 & & 100 & & 98 & \\
\hline 6 & Monitor tilting & 75 & & 72 & & 97 & \\
\hline 7 & Glare and reflection & 68 & & 60 & & 70 & \\
\hline 8 & Image stability & 91 & & 67 & & 80 & \\
\hline 9 & Ease of reading & 95 & & 68 & & 74 & \\
\hline 10 & Brightness and contrast & 92 & & 66 & & 84 & \\
\hline III & Desk & & & & & & \\
\hline 11 & Space & 81 & \multirow{5}{*}{78.4} & 100 & & 100 & \multirow{5}{*}{99.4} \\
\hline 12 & Layout & 85 & & 85 & & 99 & \\
\hline 13 & Distance from eye & 74 & & 86 & 81.4 & 100 & \\
\hline 14 & Room for leg & 93 & & 65 & & 100 & \\
\hline 15 & Hand/wrist & 59 & & 71 & & 98 & \\
\hline IV & Mouse & & & & & & \\
\hline 16 & Distance from hand & 83 & \multirow{3}{*}{77.7} & 75 & & 72 & \multirow{3}{*}{71.3} \\
\hline 17 & Run & 76 & & 78 & 71.3 & 76 & \\
\hline 18 & Operator's familiarity & 74 & & 61 & & 66 & \\
\hline$\overline{\mathrm{V}}$ & Seat & & & & & & \\
\hline 19 & Height & 89 & \multirow{6}{*}{75.3} & 100 & \multirow{6}{*}{74.7} & 99 & \multirow{6}{*}{77.7} \\
\hline 20 & Dimensions & 78 & & 72 & & 95 & \\
\hline 21 & Armrest & 76 & & 75 & & 77 & \\
\hline 22 & Backrest & 64 & & 79 & & 59 & \\
\hline 23 & Pad (foam) & 71 & & 60 & & 63 & \\
\hline 24 & Comfort and stability & 73 & & 62 & & 73 & \\
\hline VI & Space and room layout & & & & & & \\
\hline 25 & Adequate access & 90 & \multirow{7}{*}{73.7} & 65 & & 24 & \multirow{7}{*}{78.7} \\
\hline 26 & Space around seat & 86 & & 100 & & 100 & \\
\hline 27 & Layout & 80 & & 61 & & 93 & \\
\hline 28 & Location of equipment & 62 & & 61 & 68.9 & 88 & \\
\hline 29 & Monitors' positions & 51 & & 66 & & 100 & \\
\hline 30 & Obstructions and hazards & 75 & & 60 & & 100 & \\
\hline 31 & Housekeeping & 72 & & 69 & & 46 & \\
\hline VII & Illumination & & & & & & \\
\hline 32 & Lighting level & 91 & & 55 & & 60 & \\
\hline 33 & Luminaries & 66 & 72.3 & 46 & 48.8 & 99 & 86.8 \\
\hline 34 & Effectiveness & 61 & & 43 & & 97 & \\
\hline 35 & Background behind screens & 71 & & 51 & & 91 & \\
\hline VIII & Training and provision of information & & & & & & \\
\hline 36 & Use of software & 75 & & 46 & & 76 & \\
\hline 37 & Habit keying & 73 & 715 & 59 & 473 & 66 & 603 \\
\hline 38 & Adjustment & 74 & & 43 & & 65 & \\
\hline 39 & Good posture and visual fatigue & 64 & & 41 & & 34 & \\
\hline IX & Keyboard & & & & & & \\
\hline 40 & Distance & 69 & & 66 & & 98 & \\
\hline 41 & Width & 73 & 69.7 & 69 & 66.0 & 75 & 95.0 \\
\hline 42 & Height and key angle & 67 & & 63 & & 92 & \\
\hline
\end{tabular}


TABLE 3: Continued.

\begin{tabular}{|c|c|c|c|c|c|c|c|}
\hline \multirow{2}{*}{\multicolumn{2}{|c|}{ Number Ergonomics components }} & \multicolumn{2}{|c|}{$\mathrm{KAU}^{*}(N=100)$} & \multicolumn{2}{|c|}{ SAUDIA $^{* *}(N=100)$} & \multicolumn{2}{|c|}{$\operatorname{STC}^{* * *}(N=100)$} \\
\hline & & Number of positives & Average & Number of positives & Average & Number of positives & Average \\
\hline $\mathrm{X}$ & Footrest & & & & & & \\
\hline 43 & Compression of thigh & 68 & 68.0 & 65 & 65.0 & 54 & 54.0 \\
\hline XI & Document holder & & & & & & \\
\hline 44 & Need & 64 & \multirow{2}{*}{63.0} & 90 & \multirow{2}{*}{90.0} & 39 & \multirow{2}{*}{38.0} \\
\hline 45 & Balance of head posture & 62 & & 90 & & 37 & \\
\hline XII & Work organization rating & & & & & & \\
\hline 46 & Breaks & 79 & \multirow{3}{*}{59.7} & 100 & \multirow{3}{*}{73.3} & 88 & \multirow{3}{*}{89.3} \\
\hline 47 & Urgent peaks and interruptions & 40 & & 55 & & 83 & \\
\hline 48 & Over time & 60 & & 65 & & 97 & \\
\hline \multirow{4}{*}{$\begin{array}{r}\text { XIII } \\
49 \\
50\end{array}$} & Task and posture & & & & & & \\
\hline & Phoning while typing & 33 & \multirow{2}{*}{54.0} & 90 & \multirow{2}{*}{95.0} & 99 & \multirow{2}{*}{90.0} \\
\hline & Typing posture & 75 & & 100 & & 81 & \\
\hline & Total average score & & 72.3 & & 71.1 & & 81.0 \\
\hline
\end{tabular}

${ }^{*}$ KAU $=$ King Abdulaziz University.

${ }^{* *}$ SAUDIA $=$ Saudi Airlines.

${ }^{* * *}$ STC $=$ Saudi Telecom Company.

at SAUDIA were relatively older since $27 \%$ of them were younger than 35 years in comparison to $80 \%$ at STC and $68 \%$ at KAU (Table 4). The average ages at the KAU, SAUDIA, and STC were 31.5, 39.7, and 30.3 years, respectively. Yet $78 \%$ and $73 \%$ of the populations at STC and KAU have been employed for less than 10 years, in comparison to $23 \%$ at SAUDIA that began using VDT earlier than the other two institutions (Table 5). The average durations of employment at KAU, SAUDIA, and STC were 7.1, 19,7, and 7.4 years, respectively. Meanwhile, the levels of education among KAU and STC populations were higher than the SAUDIA population. For example, $65 \%$ and $41 \%$ of KAU and STC populations received higher education in comparison to only $23 \%$ at SAUDIA population. Also, $16 \%$ of the KAU and $5 \%$ of the STC populations, respectively, received graduate education (Doctor and/or Master), while none of the subject at SAUDIA population had such education level.

Most of the study populations were nonsmokers (79\%, $76 \%$, and $62 \%$ of subjects at KAU, SAUDIA, and STC, resp.) and $26 \%$ of them at STC were light smoker (smoking index less than 200) that might be added to the proportion of the nonsmoker there to be $88 \%$. This distribution might, however, be biased by the relatively young age of the examined subjects.

Considerable proportion of the populations either had no vision problems before employment (58\%, 70\%, and 58\% at KAU, SAUDIA, and STC, resp.), or were short-sighted (30\%, 23\%, and $25 \%$, resp.), while the rest were long-sighted or had other vision problems $(14 \%, 7 \%$, and $17 \%$, resp.). Similarly, more than one half of the populations at the three study locations had no musculoskeletal symptoms before employment (59\% at KAU, $62 \%$ at SAUDIA, and 55\% at STC), while considerable proportions of the populations had neck pain (22\% at KAU, $24 \%$ at SAUDIA, and $17 \%$ at STC). The rest of the populations had such symptom at one or more body locations.
More than one half of the population of KAU (52\%) was either typist $(23 \%)$ or involved in comprehensive office tasks (29\%), while $40 \%$ of them were involved in data entry (22\%) and data acquisition (22\%). However, at SAUDIA, $77 \%$ of the populations were involved in data entry (54\%) or data acquisition (23\%) while $20 \%$ of them were involved in communication tasks and none of them was typist. Similarly, at STC, $86 \%$ of the populations were involved in communication tasks (53\%) or data entry (33\%), and none of them was typist. While $58 \%$ and $61 \%$ of the populations at KAU and SAUDIA, respectively, received on-the-job training only, and the rest received formal training for different periods, the opposite existed at STC, where $72 \%$ of the population received formal training for different periods, and only $28 \%$ of the population received on-the-job training only. Consequently, $61 \%$ of the populations at KAU and $70 \%$ at SAUDIA considered their work speed as average $(56 \%$ and $70 \%$, resp.) or slow (5\% and $0 \%$, resp.), while $45 \%$ of the population at STC considered their work speed as fast and $55 \%$ of them considered their work speed as either average (49\%) or slow $(6 \%)$.

Considerable proportions of the populations at KAU and STC used computer for 7, 8, or 9 hours per day (44\% and $39 \%)$, while the whole population at SAUDIA (100\%), and $53 \%$ of them at STC, used computer for 6 hours. On the other hand, $36 \%$ of the operators at KAU used computer for 3, 4, or 5 hrs. per day, while none of them at SAUDIA, and $9 \%$ of them at STC, operated computers for these shorter periods. However, only $53 \%$ of the SAUDIA population operated computer continuously in comparison to $85 \%$ of the STC and $61 \%$ of KAU populations. Meanwhile, mostly $70 \%$ of KAU (69\%) and STC (68\%) populations had rest pauses <25\% of the work shift, and $22 \%$ of the two populations got rest pauses $30 \%-40 \%$ of the shift, while the whole SAUDIA population had $25 \%-29 \%$ of their shift as rest pauses, in comparison to $9 \%$ and $10 \%$ of the other two populations. 

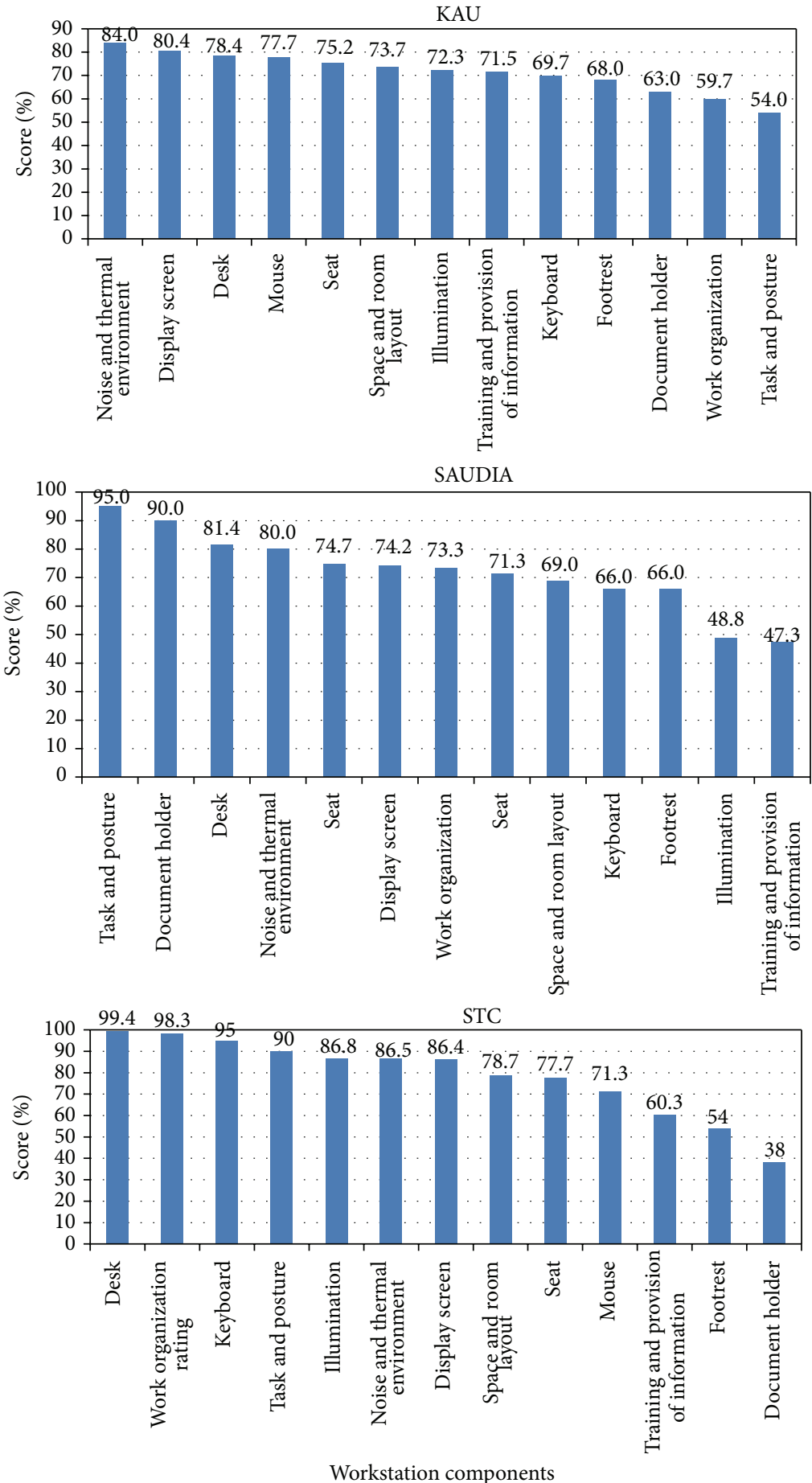

FIGURE 1: Average ergonomics scores of the examined workstation components.

Eighty-two percent of the computer users in KAU, 72\% of the operators at SAUDIA, and $60 \%$ of operators at STC were satisfied (and many were even very satisfied) at their work, particularly as related to their excellent satisfaction by their colleagues, work control, job attitude, and vigilance requirement, while the boredom from repetitive work and monotony and the work stress were the main causes of dissatisfaction among them, particularly the SAUDIA and
STC populations $(41 \%, 66 \%$, and $65 \%$ at KAU, SAUDIA, and STC, resp.).

3.3. Operators' Health Complaints. The operators' health complaints are presented in Tables 6-9. Mostly one third of the operators (35\%, 33\%, and $27 \%$ of KAU, SAUDIA, and STC populations, resp.) was suffering from body fatigue, while 
KAU

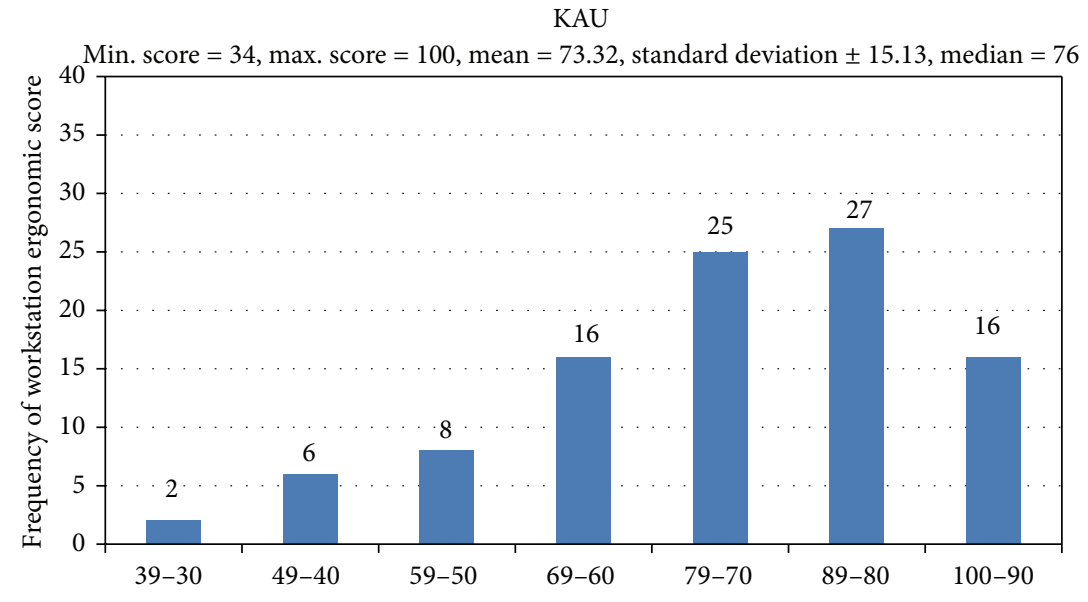

SAUDIA

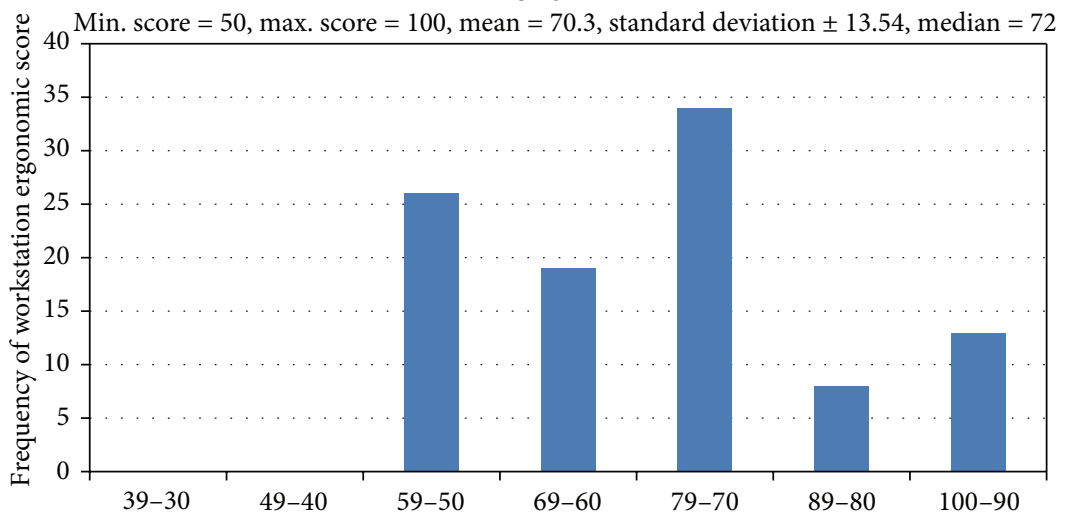

STC

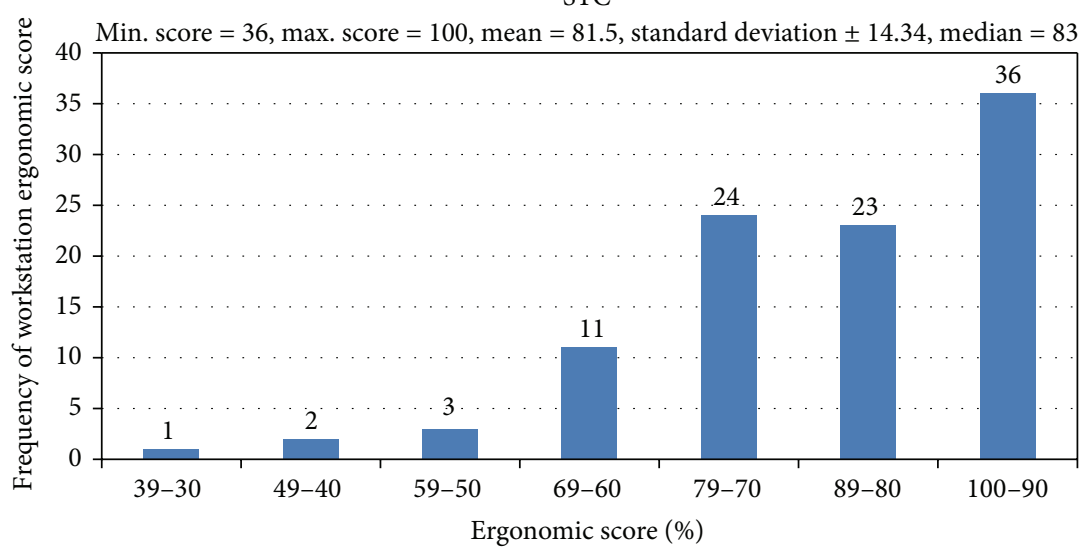

FIGURE 2: Distribution of the ergonomics scores of the examined workstation component.

$23 \%, 21 \%$, and $37 \%$ of them were suffering from headache, such complaints occurred mostly sometimes among all the populations, however occurred to less extent, particularly among SAUDIA and STC operators. The lack of concentration occurred to less extent (for example, $8 \%, 6 \%$, and $20 \%$ among KAU, SAUDIA, and STC populations, resp.), particularly and daily among SAUDIA and STC populations (Table 6).

Only $41 \%$ and $46 \%$ of KAU and STC populations, in comparison to $61 \%$ of SAUDIA population, reported eye and vision symptoms. The most predominant eye symptoms were eye redness, tearing, pain, and redness, and the most predominant vision symptoms were blurring, particularly for distance objects, as well as sensitivity to light (Table 7).

Thirty percent, $49 \%$, and $39 \%$ of the KAU, SAUDIA, and STC populations were free from musculoskeletal symptoms. The main occurring symptoms were aching, tingling, numbness, pain, and stiffness, which occurred, mostly sometimes, and, to a less extent, often (Table 8). The highest incidences of the symptoms were at the operators' higher and lower back, 
TABLE 4: Demographic characteristics of the study population.

\begin{tabular}{|c|c|c|c|}
\hline \multirow{2}{*}{ Demographic characteristics } & \multicolumn{3}{|c|}{ Frequency } \\
\hline & $\operatorname{KAU}(N=100)$ & SAUDIA $(N=100)$ & $\operatorname{STC}(N=100)$ \\
\hline \multicolumn{4}{|l|}{ Age (years) } \\
\hline $20-24$ & 24 & 9 & 19 \\
\hline $25-29$ & 30 & 8 & 47 \\
\hline $30-34$ & 14 & 10 & 14 \\
\hline $35-39$ & 15 & 18 & 7 \\
\hline $40-44$ & 10 & 20 & 8 \\
\hline $45-49$ & 5 & 24 & 3 \\
\hline $50-54$ & 2 & 9 & 2 \\
\hline$>55$ & 0 & 2 & 0 \\
\hline \multicolumn{4}{|l|}{ Education } \\
\hline Middle & 6 & 2 & 2 \\
\hline Secondary (general) & 21 & 71 & 55 \\
\hline Secondary (technical) & 8 & 4 & 2 \\
\hline High (technical) & 19 & 2 & 13 \\
\hline High (administrative) & 30 & 21 & 23 \\
\hline Graduate (master + doctor) & 16 & 0 & 5 \\
\hline \multicolumn{4}{|l|}{ Smoking index } \\
\hline Nonsmokers & 79 & 76 & 62 \\
\hline$<100$ & 6 & 5 & 17 \\
\hline $100-199$ & 3 & 2 & 9 \\
\hline $200-399$ & 2 & 4 & 5 \\
\hline $400-500$ & 5 & 3 & 3 \\
\hline$>600$ & 5 & 10 & 4 \\
\hline \multicolumn{4}{|c|}{ Vision symptoms prior to present work ${ }^{*}$} \\
\hline None & 58 & 70 & 58 \\
\hline Short-sighted & 30 & 23 & 25 \\
\hline Long-sighted & 7 & 2 & 10 \\
\hline Others & 7 & 5 & 7 \\
\hline \multicolumn{4}{|c|}{ Musculoskeletal symptoms prior to present Work* } \\
\hline None & 59 & 62 & 55 \\
\hline Neck pain & 22 & 24 & 17 \\
\hline Shoulder and/or arms pain & 11 & 11 & 4 \\
\hline Lower trunk pain & 13 & 23 & 16 \\
\hline Thigh and leg pain & 5 & 8 & 4 \\
\hline Others & 1 & 1 & 4 \\
\hline
\end{tabular}

${ }^{*}$ The same subject might have more than one symptom occurring at different frequencies.

neck and shoulder, arm, elbow, forearm, and fingers and then at the lower limbs (buttock to foot) (Table 9).

3.4. Factors Affecting Incidence of Complaints. The effects of age and duration of employment (i.e., work) on the incidence of operators' health complaints are shown in Tables 10 and 11. There has been general trend of increasing the different complaints by age, particularly among those exceeding 35 years of age (Table 10). This observation is further confirmed in Table 11, where the operators working for $>10$ years had, generally, the highest incidences of the general and the eye and vision complaints, as well as the incidences of other complaints, but to a less extent.
The impact of the ergonomics score of the workstation on the incidence of operators' complaints is shown in Table 12, where there has been a trend of decrease in the incidence of operators' general complaints, eye and vision complaints, and musculoskeletal complaints, particularly the extremities and the lower trunk complaints, by the increase of the ergonomics score of their workstations.

Out of the many factors considered for their effects on the incidences of the operators' complaints and symptoms, the smoking habit, the type of work, workers satisfaction, and the operators' history of musculoskeletal complaints and of eye and vision before joining present work showed some effects as indicated in Tables 13-17. Smoking appears to have some 
TABLE 5: Occupational characteristics of the study population.

\begin{tabular}{|c|c|c|c|}
\hline \multirow{2}{*}{ Occupational characteristics } & \multicolumn{3}{|c|}{ Frequency } \\
\hline & $\operatorname{KAU}(N=100)$ & SAUDIA $(N=100)$ & $\operatorname{STC}(N=100)$ \\
\hline \multicolumn{4}{|l|}{ Duration of employment (years) } \\
\hline$<1$ & 12 & 7 & 7 \\
\hline $1-2$ & 23 & 5 & 24 \\
\hline $3-4$ & 20 & 4 & 17 \\
\hline $5-9$ & 18 & 7 & 30 \\
\hline $10-14$ & 11 & 7 & 5 \\
\hline $15-19$ & 7 & 14 & 9 \\
\hline $20-24$ & 5 & 20 & 5 \\
\hline $25-29$ & 3 & 16 & 3 \\
\hline $30-34$ & 1 & 16 & 0 \\
\hline$\geq 35$ & 0 & 4 & 0 \\
\hline \multicolumn{4}{|l|}{ Type of work } \\
\hline Data entry & 22 & 54 & 33 \\
\hline Data acquisition & 18 & 23 & 9 \\
\hline Typist & 23 & 0 & 0 \\
\hline Communication task & 8 & 20 & 53 \\
\hline Comprehensive office tasks & 29 & 3 & 5 \\
\hline Duration of formal training (days) On-the-job training only & 58 & 61 & 28 \\
\hline$<50$ & 12 & 19 & 24 \\
\hline $50-99$ & 5 & 8 & 14 \\
\hline $100-199$ & 11 & 2 & 20 \\
\hline $200-299$ & 4 & 2 & 4 \\
\hline $300-399$ & 4 & 4 & 1 \\
\hline $400-499$ & 3 & 0 & 1 \\
\hline$\geq 500$ & 3 & 4 & 8 \\
\hline \multicolumn{4}{|l|}{ Work speed } \\
\hline Fast & 39 & 30 & 45 \\
\hline Average & 56 & 70 & 49 \\
\hline Slow & 5 & 0 & 6 \\
\hline \multicolumn{4}{|l|}{ Computer use (hrs/day) } \\
\hline 3 & 15 & 0 & 2 \\
\hline 4 & 12 & 0 & 3 \\
\hline 5 & 9 & 0 & 3 \\
\hline 6 & 20 & 100 & 53 \\
\hline 7 & 14 & 0 & 1 \\
\hline 8 & 22 & 0 & 17 \\
\hline 9 & 8 & 0 & 21 \\
\hline \multicolumn{4}{|l|}{ Nature of daily work on computer } \\
\hline Continuous & 61 & 53 & 85 \\
\hline Intermittent & 39 & 47 & 15 \\
\hline \multicolumn{4}{|l|}{ Rest pauses of work shift (\%) } \\
\hline $5-9$ & 10 & 0 & 12 \\
\hline $10-14$ & 22 & 0 & 19 \\
\hline $15-19$ & 18 & 0 & 16 \\
\hline $20-24$ & 19 & 0 & 21 \\
\hline $25-29$ & 9 & 100 & 10 \\
\hline $30-34$ & 9 & 0 & 11 \\
\hline $35-39$ & 7 & 0 & 6 \\
\hline$\geq 40$ & 6 & 0 & 5 \\
\hline
\end{tabular}


TABLE 5: Continued.

\begin{tabular}{|c|c|c|c|}
\hline \multirow{2}{*}{ Occupational characteristics } & \multicolumn{3}{|c|}{ Frequency } \\
\hline & $\operatorname{KAU}(N=100)$ & SAUDIA $(N=100)$ & $\operatorname{STC}(N=100)$ \\
\hline \multicolumn{4}{|l|}{ Elements of work satisfaction } \\
\hline Satisfaction by foreman and colleagues interrelations & 100 & 99 & 99 \\
\hline Satisfaction by absence work stress & 68 & 60 & 61 \\
\hline Satisfaction of work control & 96 & 94 & 96 \\
\hline Satisfaction of job attitude & 92 & 81 & 82 \\
\hline Satisfaction by vigilance requirement & 94 & 100 & 94 \\
\hline Satisfaction by nature of work & 73 & 85 & 55 \\
\hline Satisfaction by absence of repetitive work and monotony & 59 & 34 & 35 \\
\hline \multicolumn{4}{|l|}{ Evaluation of work satisfaction* } \\
\hline Very satisfied & 39 & 35 & 29 \\
\hline Satisfied & 43 & 37 & 31 \\
\hline Satisfied to some extent & 10 & 14 & 27 \\
\hline Not satisfied & 8 & 14 & 13 \\
\hline
\end{tabular}

${ }^{*}$ Percent of duration(s) of rest pauses to duration of work shift.

effect on increasing the incidences of the general and eye and vision complaints, particularly among KAU computer users and SAUDIA operators, and on the lower extremities and lower trunk complaints, to some extent (Table 13).

It is worth noting that the lowest eye and vision complaints occurred among the operators who had the lowest level of education (i.e., middle education), which might be interpreted by their relatively lower involvement in vision tasks than the operators having higher levels of education.

As related to the impact of type of work on the incidence of complaints, results in Table 14 show that the operators who were involved in communication tasks in KAU, and in data acquisition in SAUDIA, had the lowest general, eye and vision, neck and shoulder, lower extremities, and lower trunk complaints, as well as those involved in comprehensive activities among all the populations, meanwhile showing the highest freedom from all complaints. It may be noted that the numbers of operators involved in these activities (KAU communication tasks and SAUDIA and STC comprehensive tasks $=8,3$, and 5 , resp.) were the lowest among all worker involved in other types of activities which might have some effect on the results.

Nevertheless, the work satisfaction showed clear impact on the incidence of health complaints among the examined computer users, where the percentages of those who were free from complaints got higher by the improvement of work satisfaction (Table 15); meanwhile, the lowest incidences of mostly all the complaints were the lowest among the very satisfied operators, particularly the SAUDIA and STC operators.

The history of previous ailments among computer users/operators, also, had some impact on the reported complaints among them, where the percentages of the present complaints among the subjects who had no previous ailments were less than among the other subjects reporting related ailments' history (Tables 16-18).

\section{Conclusions}

The average ergonomics score at STC was $81 \%$ which may be considered as a good level. However, and unexpectedly, the average ergonomics scores at KAU and SAUDIA were only $73.3 \%$ and $70.3 \%$, respectively. It had been anticipated that the average ergonomics scores for the computer workstations existing in leading institutions like KAU and SAUDIA should be considerably higher.

Although the examined populations in KAU and STC were relatively young and, consequently, had relatively short employment work duration, were relatively highly educated, had relatively low smoking index and low history of ailments before employment, had some type of on-the-job and/or formal training, mostly use computer daily for $<7$ hours and continuously getting rest pauses, and were mostly satisfied at work, yet they had somewhat high incidences of general complaints (e.g., body fatigue, headache, and lack of concentration), vision complaints, and musculoskeletal complaints. However, within SAUDIA population, surprisingly, the highest health complaints were among the youngest operators, who also had the lowest duration of computer work, as well as among those who had on-the-job and/or formal training; meanwhile, no systematic effect of the workstations' ergonomic scores on the incidence of the complaints was observed. These anomalies might be attributed to having some of the operators who developed complaints there left or changed their work.

Naturally, the operators who were satisfied by their work and those who were conducting comprehensive works (i.e., variable types of work) as well as those who had no, or inconsiderable, history of previous ailments had the least incidence of the health complaints.

Meanwhile, higher incidences of the complaints existed among the smoking operators and those who did not work continuously with computer, as well as those who rated themselves as fast operating. 


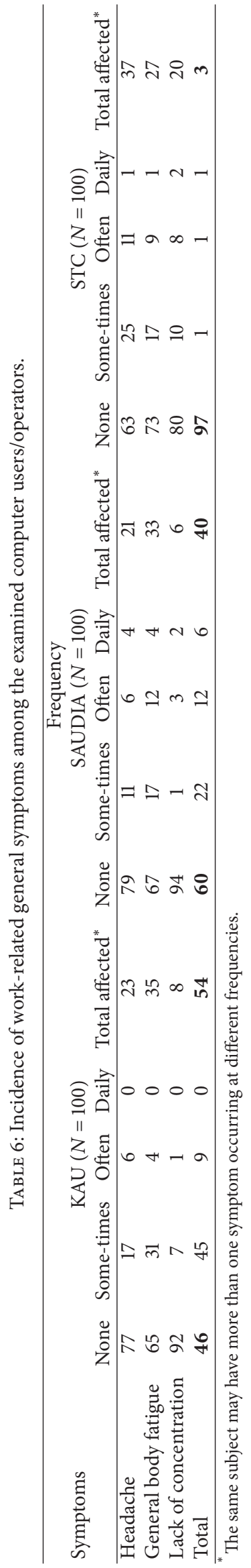




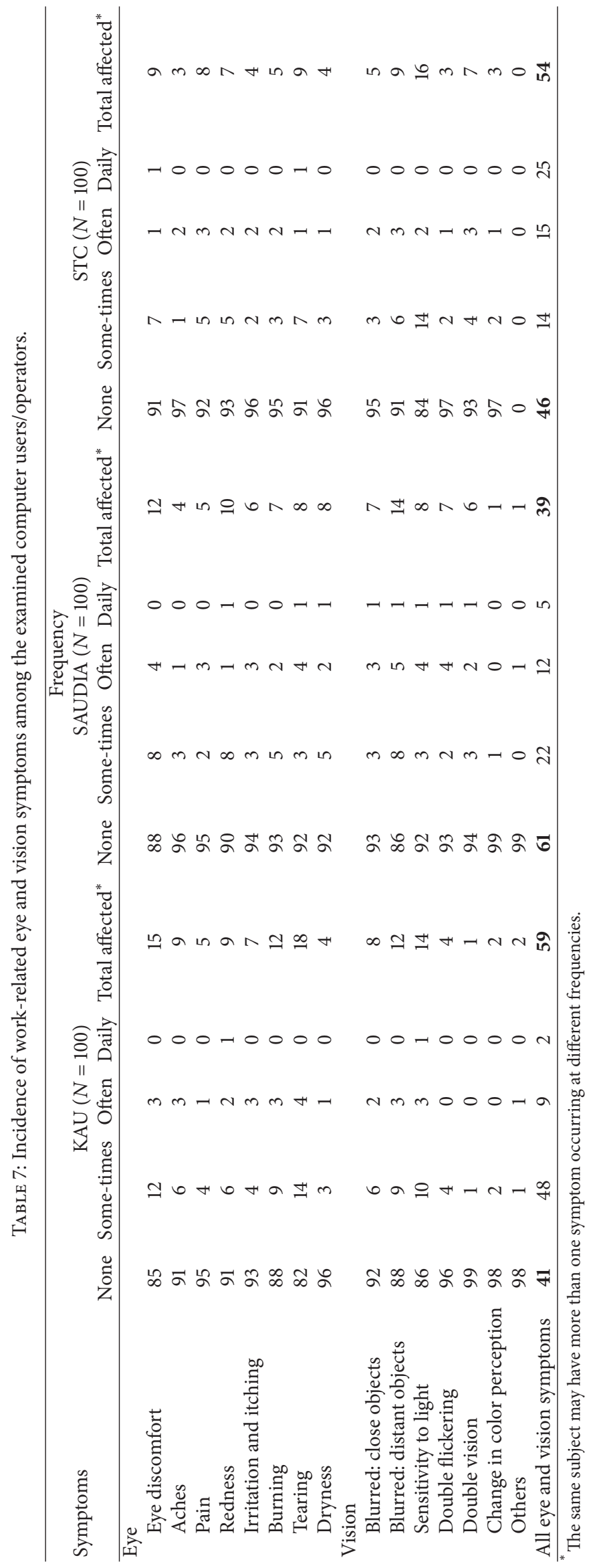




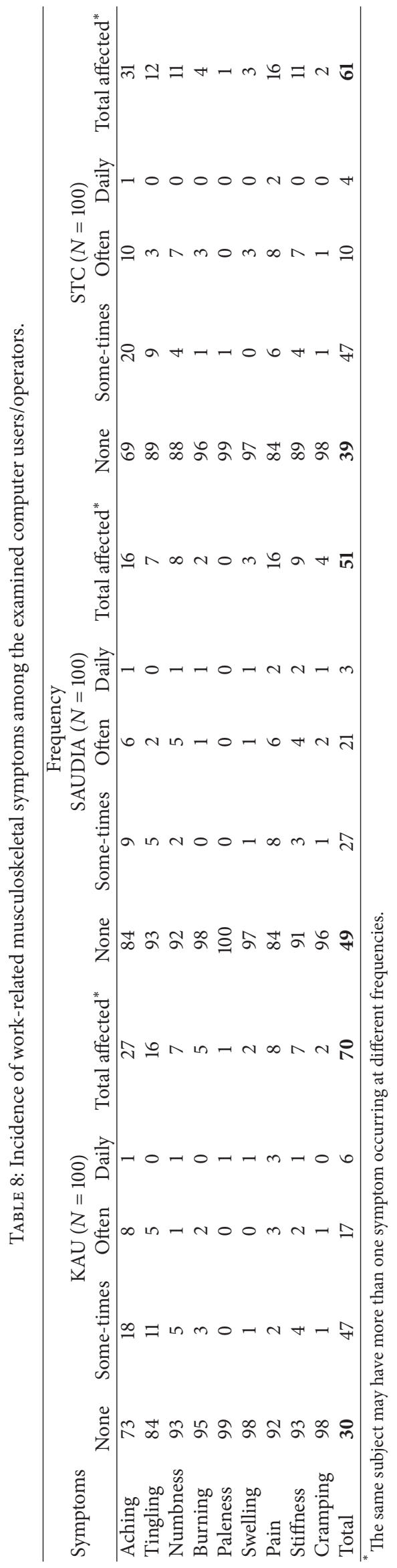




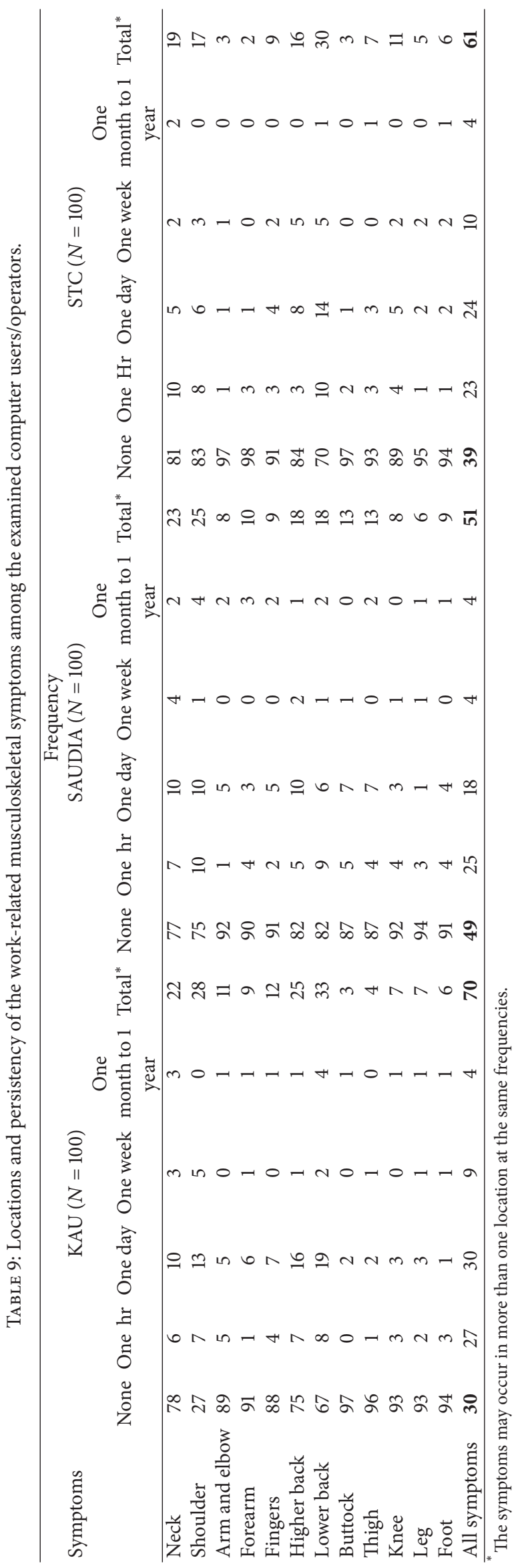




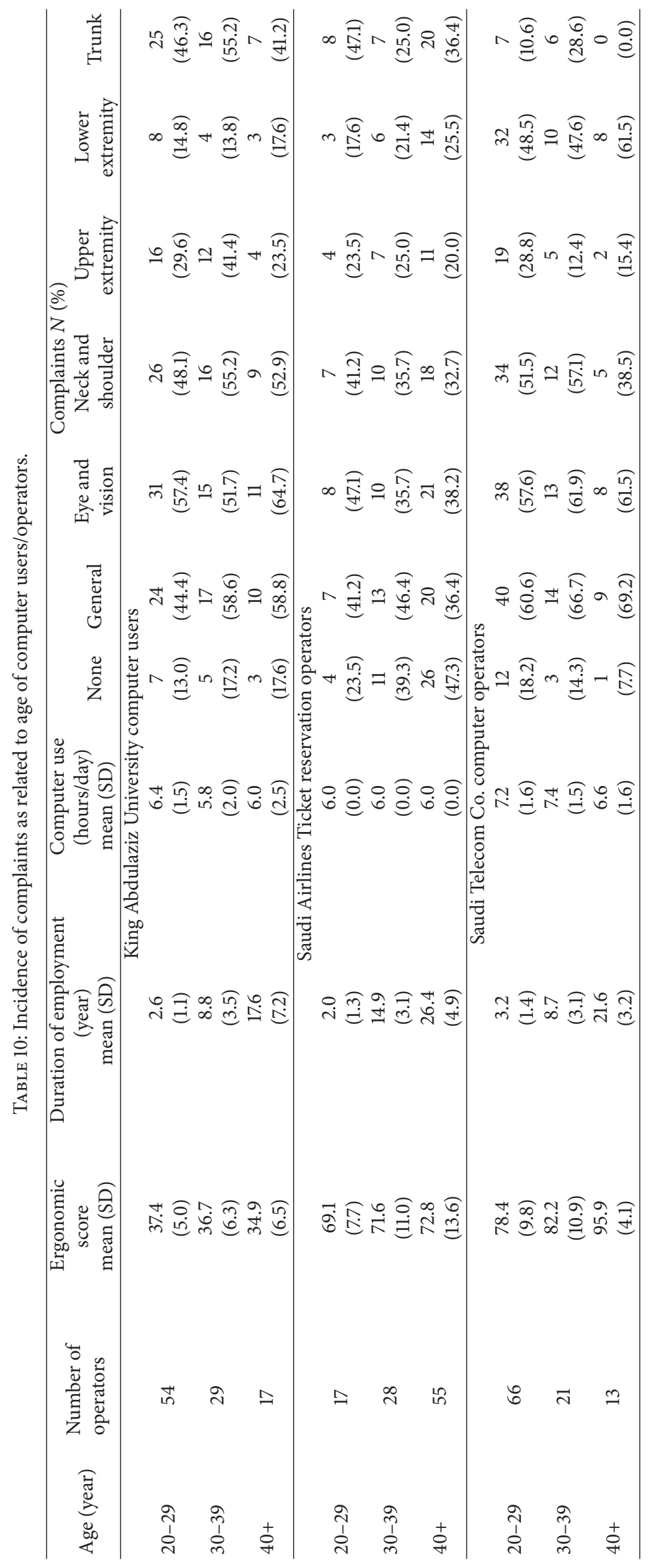




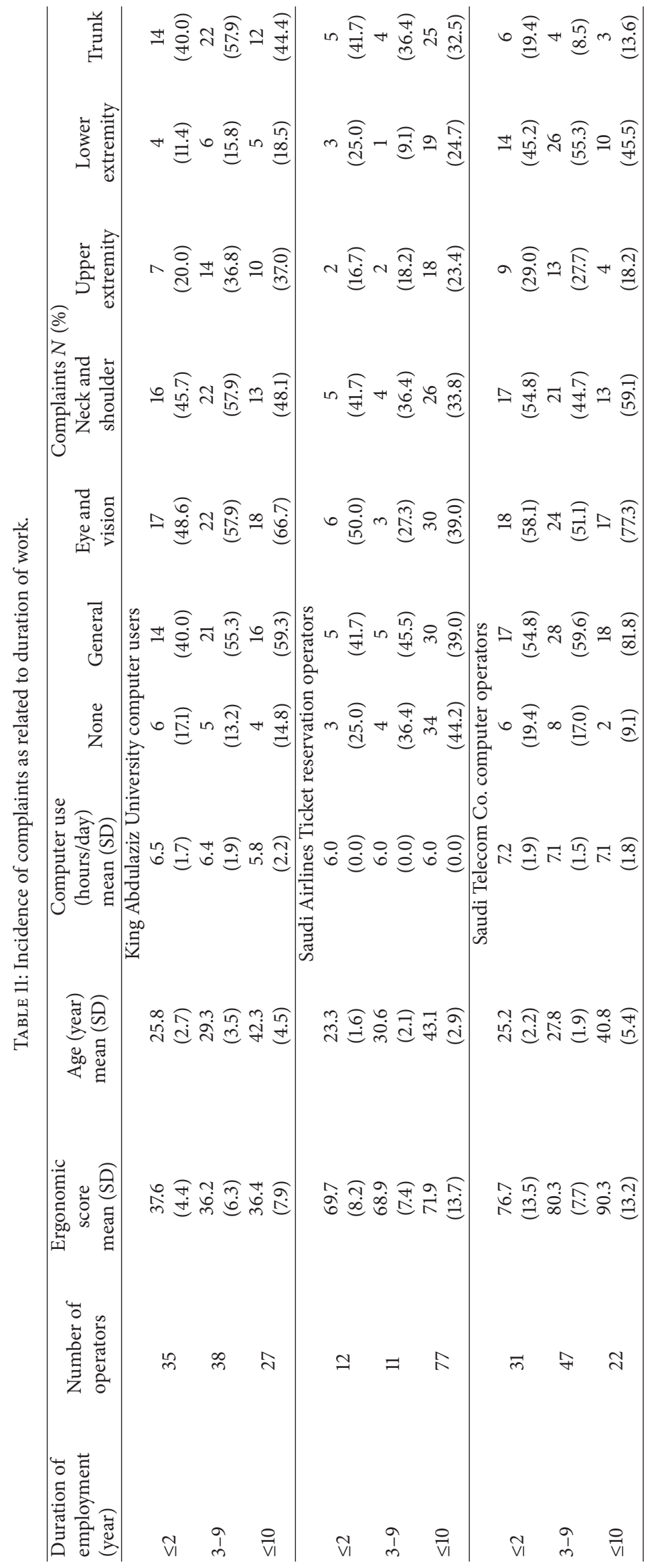




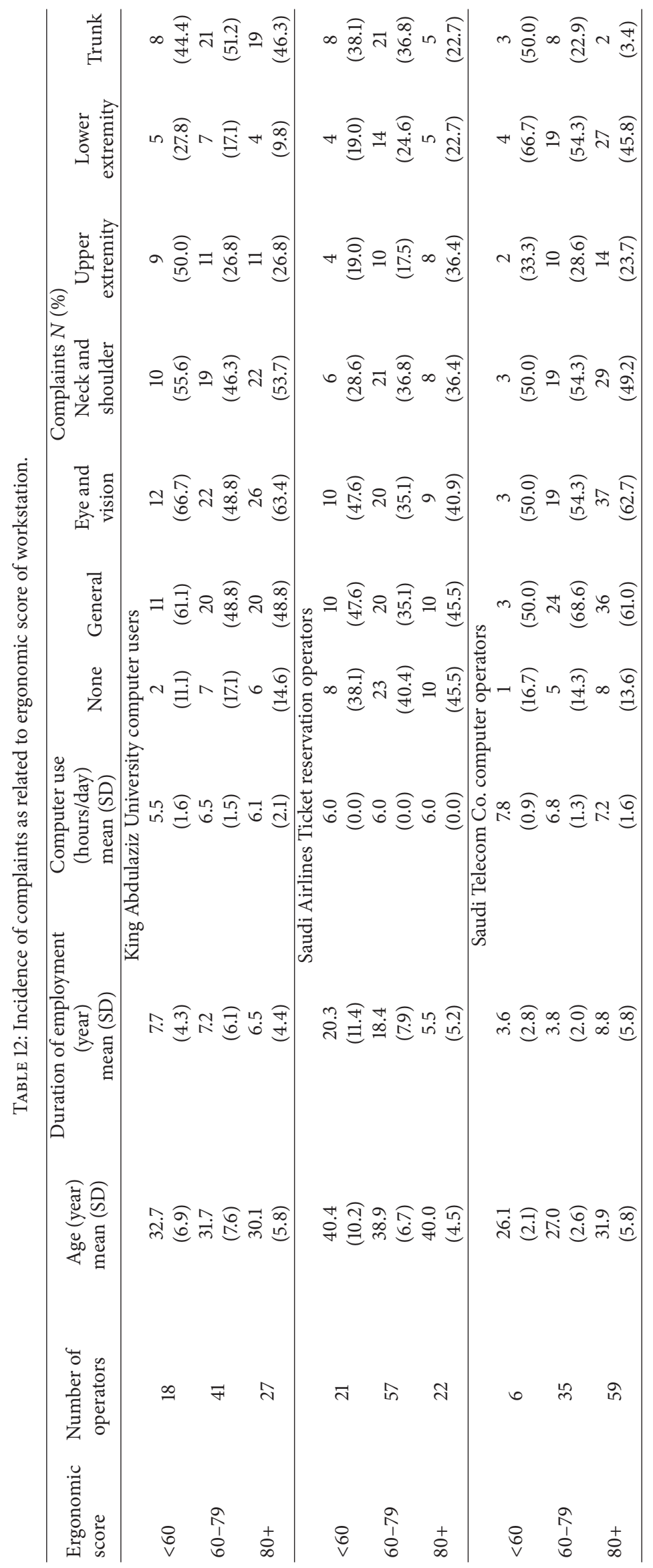




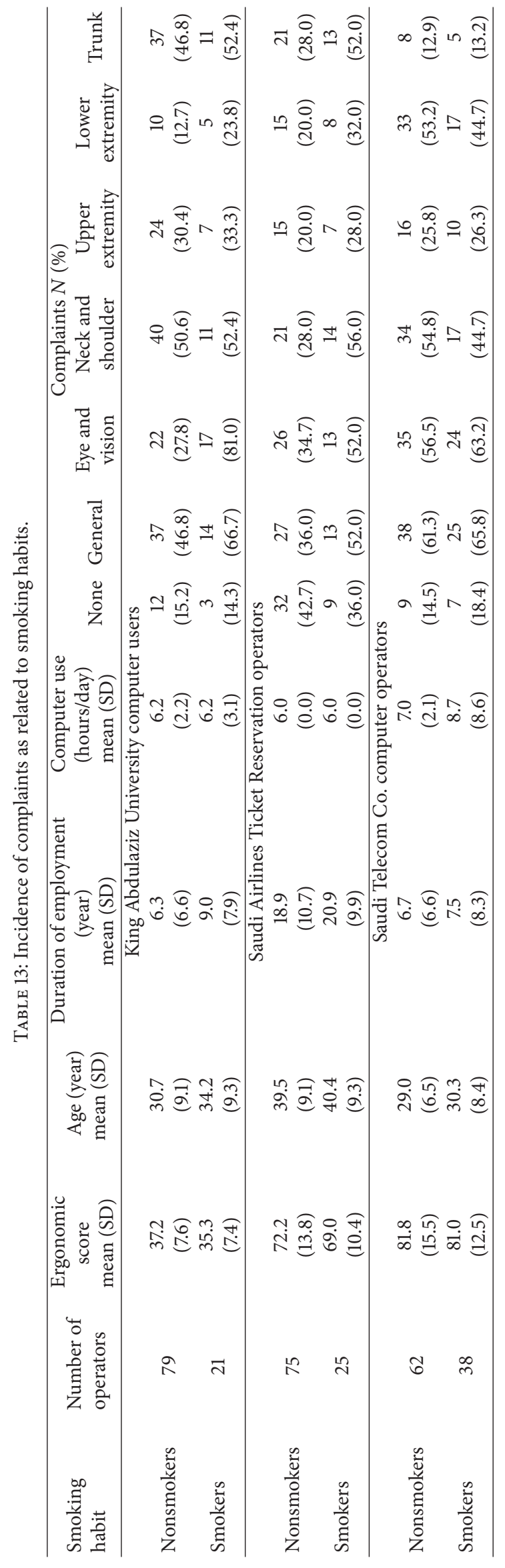




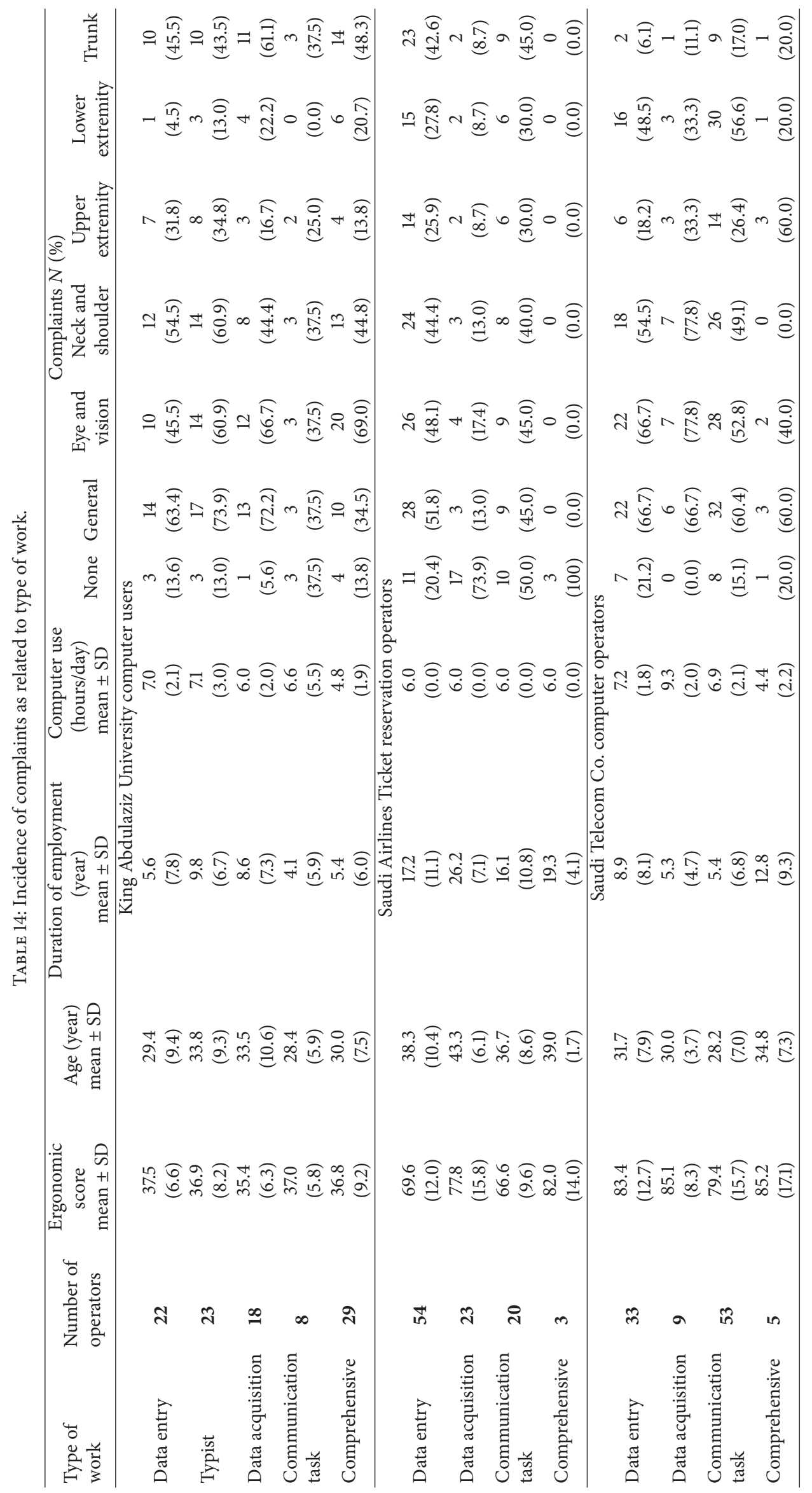




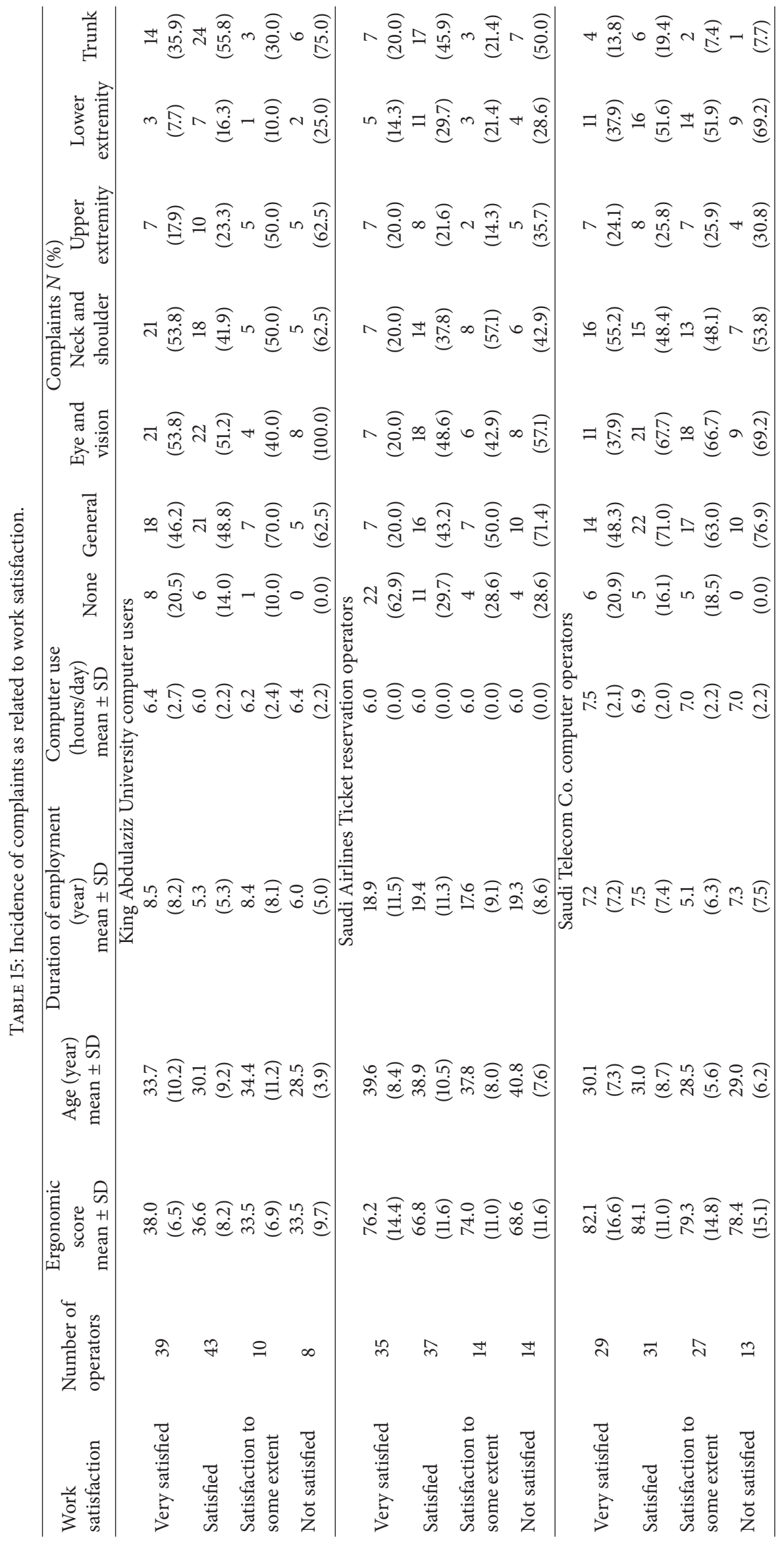


TABLE 16: Incidence of eye and vision complaints as related to previous ailments of computer users/operators.

\begin{tabular}{|c|c|c|c|c|c|c|c|c|}
\hline \multirow{2}{*}{ Complaints } & \multirow{2}{*}{$\begin{array}{l}\text { Number of } \\
\text { operators }\end{array}$} & \multirow{2}{*}{$\begin{array}{l}\text { Ergonomic } \\
\text { score } \\
\text { mean } \pm \text { SD }\end{array}$} & \multirow{2}{*}{$\begin{array}{l}\text { Age (year) } \\
\text { mean } \pm \text { SD }\end{array}$} & \multirow{2}{*}{$\begin{array}{c}\text { Duration of employment } \\
\text { (year) } \\
\text { mean } \pm \text { SD }\end{array}$} & \multirow{2}{*}{$\begin{array}{l}\text { Computer use } \\
\text { (hours/day) } \\
\text { mean } \pm \text { SD }\end{array}$} & \multicolumn{3}{|c|}{ Complaints $N(\%)$} \\
\hline & & & & & & None & General & $\begin{array}{c}\text { Eye and } \\
\text { vision }\end{array}$ \\
\hline \multicolumn{9}{|c|}{ King Abdulaziz University computer users } \\
\hline None & 58 & 36.6 & 30.9 & 5.4 & 6.0 & 12 & 27 & 25 \\
\hline & & $(7.5)$ & $(9.2)$ & $(5.6)$ & $(2.0)$ & $(20.7)$ & $(46.6)$ & $(43.1)$ \\
\hline Short-sighted & 30 & 37.6 & 31.3 & 5.4 & 6.6 & 1 & 20 & 25 \\
\hline & & $(8.3)$ & $(8.8)$ & $(5.6)$ & $(3.2)$ & $(3.3)$ & $(66.7)$ & $(83.3)$ \\
\hline Long-sighted & 7 & 37.2 & 40.4 & 18.0 & 5.7 & 1 & 3 & 3 \\
\hline Long-signted & 7 & $(6.7)$ & $(11.4)$ & $(10.8)$ & $(2.0)$ & $(14.3)$ & $(42.9)$ & $(42.9)$ \\
\hline Others & 7 & 36.5 & 39.8 & 11.9 & 5.6 & 1 & 2 & 5 \\
\hline Uincts & 1 & $(4.9)$ & $(13.7)$ & $(12.3)$ & $(2.1)$ & $(14.3)$ & $(28.6)$ & $(71.4)$ \\
\hline \multicolumn{9}{|c|}{ Saudi Airlines Ticket reservation operators } \\
\hline None & 70 & 71.4 & 38.9 & 18.5 & 6.0 & 41 & 18 & 13 \\
\hline None & 70 & $(13.0)$ & $(9.1)$ & $(10.9)$ & $(0.0)$ & $(58.6)$ & $(25.7)$ & $(18.6)$ \\
\hline Short-sighted & 23 & 72.2 & 38.7 & 18.9 & 6.0 & 0 & 17 & 19 \\
\hline 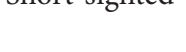 & & $(13.2)$ & (10.6) & (11.4) & $(0.0)$ & $(0.0)$ & (73.9) & $(82.6)$ \\
\hline Long-sighted & 2 & 65.0 & 47.5 & 26.5 & 6.0 & 0 & 2 & 2 \\
\hline & & (12.8) & $(0.7)$ & $(0.7)$ & $(0.0)$ & $(0.0)$ & $(100.0)$ & $(100.0)$ \\
\hline Others & 5 & 68.8 & 43.6 & 22.8 & 6.0 & 0 & 3 & 5 \\
\hline & 3 & (19.0) & $(4.8)$ & (6.1) & $(0.0)$ & $(0.0)$ & $(60.0)$ & $(100.0)$ \\
\hline \multicolumn{9}{|c|}{ Saudi Telecom Co. computer operators } \\
\hline None & 58 & 80.4 & 29.1 & 5.8 & 7.2 & 13 & 29 & 24 \\
\hline None & 58 & $(14.9)$ & $(6.9)$ & $(6.0)$ & $(2.0)$ & $(22.4)$ & $(50.0)$ & $(41.4)$ \\
\hline Short-sighted & 24 & 84.8 & 30.3 & 8.1 & 6.7 & 3 & 19 & 20 \\
\hline Snort-signted & 24 & $(12.9)$ & $(6.2)$ & (7.6) & (2.1) & $(12.5)$ & $(79.2)$ & $(83.3)$ \\
\hline Long-sighted & 11 & 80.0 & 30.5 & 6.6 & 7.2 & 0 & 8 & 8 \\
\hline Long-signted & II & (13.5) & (9.5) & (8.4) & (2.1) & $(0.0)$ & $(72.7)$ & $(72.7)$ \\
\hline Others & 7 & 86.0 & 32.7 & 10.0 & 7.4 & 0 & 7 & 7 \\
\hline Utilets & 1 & (14.6) & (9.3) & (10.3) & (2.7) & $(0.0)$ & $(100.0)$ & $(100.0)$ \\
\hline
\end{tabular}

In summary, the incidence of the various complaints had been demonstrated, generally, to increase by (a) the decrease in the ergonomics score of the workstations, (b) the progress of age and duration of employment, (c) the increase of smoking habit, (d) the continuous daily use of computer, (e) the lack of work satisfaction, and (f) the history of operators' previous ailments. However, unexpectedly, no effect could be demonstrated of the operators' formal training and the daily hours of computer use, on the incidences of the complaints.

It is anticipated that the incidences of the different complaints among the examined population increased by their progress in the duration of work. Therefore, it is recommended that rapid actions should be taken to improve the ergonomics of the computer workstations. The improvement of each workstation should be considered separately with reference to the evaluation checklist of its individual components.

Setting up training programs for computer operators to efficiently use their computers and optimize their posture and movements inside their computer workstations based on ergonomics principles is highly recommended. Also, motivation of workers to learn about computer work-related health disorders, their causes, etiology, preferable postures and movements, and the role of fitness exercise, and encouraging them to take rest pauses within their work shifts, all are recommended.

It is recommended to conduct preplacement examination for computers' operators to exclude subjects with history of ailments that might be aggravated by computer use and to have available health baseline for the employed subjects as well as periodical medical examination (annually or each two years) to assure normal health background and to early discover any deviation from normality.

Finally, the study recommends extending the research to cover the sectors of computer and VDTs users, particularly those employed by small offices and medium-size enterprises where it is anticipated to have ergonomics poorly designed workstations. Also, particular interest may be forwarded to investigating the presently studied complaints among the female computer users in KSA. 


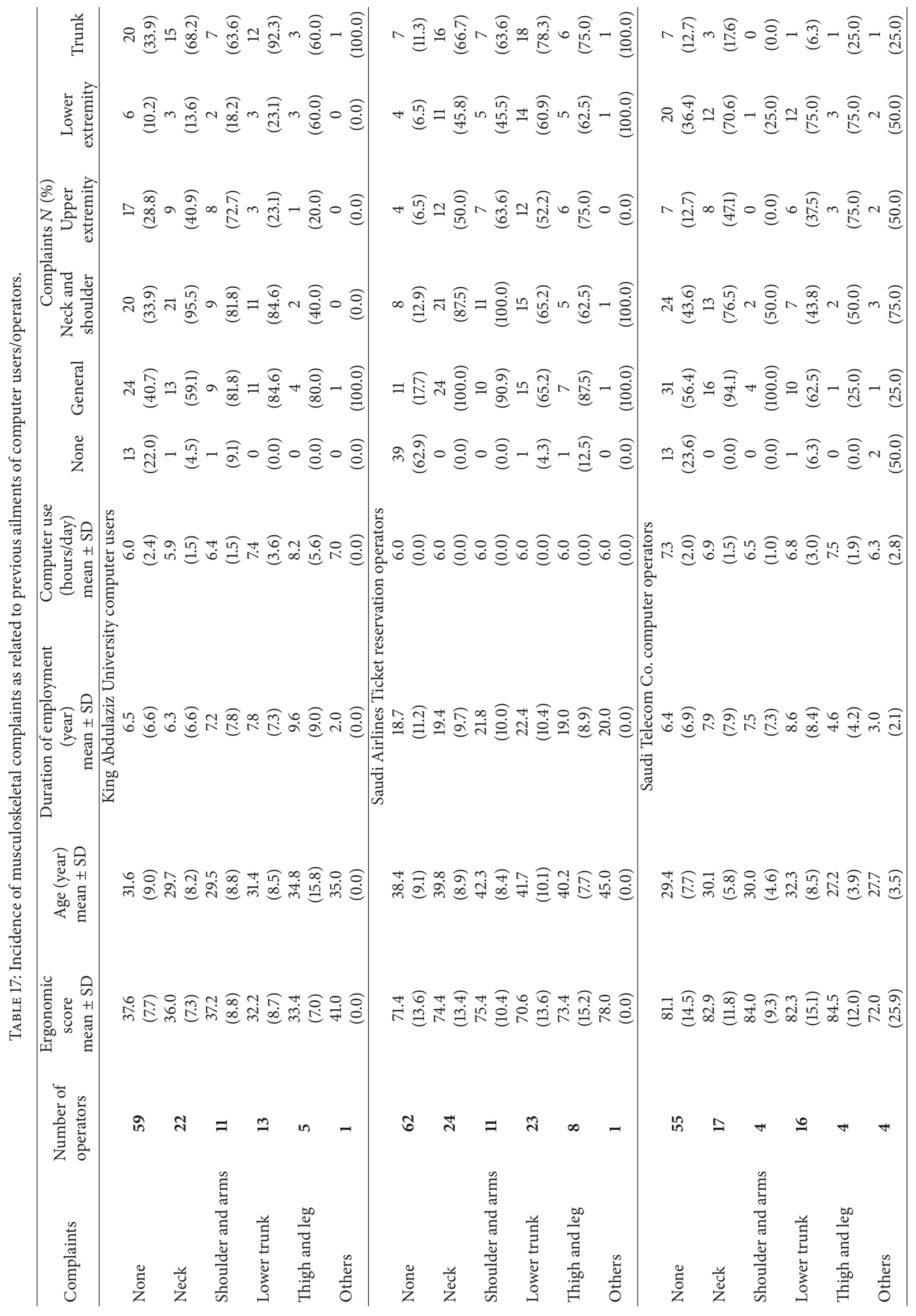




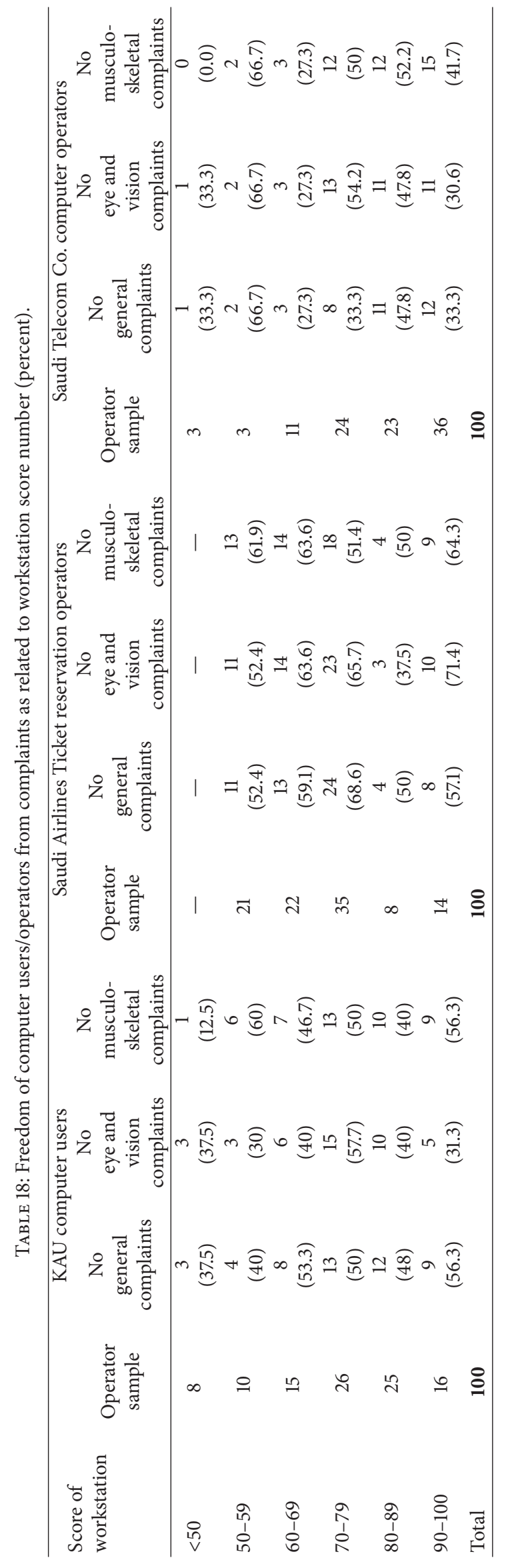




\section{Conflict of Interests}

The author declares that there is no conflict of interests regarding the publication of this paper.

\section{References}

[1] National Institute for Occupational Safety and Health (NlOSH ), "Potential health hazards of video display terminals," DHHS (NIOSH) publication no. 81-129, Cincinnati, Ohio, USA, 1981.

[2] World Health Organization (WHO), "Provisional statements of WHO working group on occupational health aspects in the use of visual display units," VDT News, vol. 3, no. 1, 13, 1986.

[3] V. M. Reading and R. A. Weale, "Eye strain and visual display units," The Lancet, vol. 1, no. 8486, pp. 905-906, 1986.

[4] Council on Scientific Affairs and American Medical Association, "Health effects of video display terminals," Journal of the American Medical Association, vol. 257, no. 11, pp. 1508-1512, 1987.

[5] World Health organization (WHO), Visual Display Terminals and Workers' Health, WHO, Geneva, Switzerland, 1987.

[6] ANSI/HFS, "American National Standard for Human Factors Engineering of Visual Display Terminal Workstation," ANSI/HFS Standard no. 100-1988, Human Factors Society, Santa Monica, Calif, USA, 1988.

[7] American Industrial Hygiene Association (AIHA), Ergonomics Interventions to Prevent Musculoskeletal Injuries in Industry, AIHA publication, Lewis publishers, Chelsea, Mich, USA, 1989.

[8] E. G. Goding and J. S. Hacunda, Computer and Visual Stress, Seacoast Information Services, Charlestown, RI, USA, 1990.

[9] M. J. Collins, B. Brown, K. J. Bowman, and A. Carkeet, "Symptoms associated with VDT use," Clinical and Experimental Optometry, vol. 73, no. 4, pp. 111-118, 1990.

[10] J. E. Sheedy and S. D. Parsons, "The video display terminal eye clinic: clinical report," Optometry and Vision Science, vol. 67, no. 8, pp. 622-626, 1990.

[11] J. E. Sheedy, "Video display terminals, solving the vision," Problems in Optometry, vol. 2, no. 1, pp. 1-16, 1990.

[12] J. Sheedy, "Video display terminals, solving the environmental problems," Problems in Optometry, vol. 2, no. 1, pp. 17-31, 1990.

[13] J. E. Sheedy, "Vision problems at video display terminals: a survey of optometrists," Journal of the American Optometric Association, vol. 63, no. 10, pp. 687-692, 1992.

[14] K. Tsubota and K. Nakamori, "Dry eyes and video display terminals," The New England Journal of Medicine, vol. 328, no. 8, p. 584, 1993.

[15] National Institute for Occupational Safety and Health (NIOSH), Cumulative Trauma Disorders in Workplace: Bibliography, NIOSH, Cincinnati, Ohio, USA, 1995.

[16] D. J. Oborne, Ergonomics at Work, John Wiley \& Sons, New York, NY, USA, 3rd edition, 1995.

[17] S. Konz, Work Design, Publishing Horizon, Scottsdale, Ariz, USA, 4th edition, 1995.

[18] World Health Organization (WHO), Global Strategy on Occupational Health for All, WHO, Geneva, Switzerland, 1995.

[19] J. Sheedy, Vision at Computer Displays, Vision Analysis, Walnut Creek, Calif, USA, 1995.

[20] J. E. Sheedy, "The bottom line on fixing computer-related vision and eye problems.," Journal of the American Optometric Association, vol. 67, no. 9, pp. 512-517, 1996.
[21] National Safety Council (NSC), ANSI Control of Work-Related Cumulative Trauma Disorders, ANSI Z365NSC, National Safety Council, Itasca, Ill, USA, 1996.

[22] A. Bhattacharya and J. D. McGlothlin, Occupational Ergonomics: Theory and Applications, Marcel Dekker, New York, NY, USA, 1996.

[23] J. Faucett and D. M. Rempel, "Musculoskeletal symptoms related to video display terminal use: an analysis of objective and subjective exposure estimates," The American Association of Occupational Health Nursing Journal, vol. 44, no. 1, pp. 33-39, 1996.

[24] K. H. Kroemer and E. Grandjean, Fitting the Human to the Task, Taylor and Francis, T.J. International, Padstow Cornwall, UK, 5th edition, 1997.

[25] L. Punnett and U. Bergqvist, "Visual display unit work and upper extremity musculoskeletal disorders: a review of epidemiological findings," National Institute for Working Life, 1997.

[26] American Optometric Association (AOA), The Effects Of Computer Use on Eye Health and Vision, American Optometric Association (AOA), St. Louis, Mo, USA, 1997.

[27] S. Kumar, "Selected theories of musculoskeletal injury causation," in Biomechanics in Ergonomics, S. Kumar, Ed., pp. 3-24, Taylor \& Francis, Padstow, UK, 1999.

[28] K. Kroemer and K. Kroemer-Elbert, Ergonomics: How to Design for Ease and Efficiency, Prentice Hall, Upper Saddle River, NJ, USA, 2000.

[29] B. Demure, R. S. Luippold, C. Bigelow, D. Ali, K. A. Mundt, and B. Liese, "Video display terminal workstation improvement program: I. Baseline associations between musculoskeletal discomfort and ergonomic features of workstations," Journal of Occupational and Environmental Medicine, vol. 42, no. 8, pp. 783-791, 2000.

[30] Canadian Standards Association (CSA), A Guideline on Office Ergonomics (CAN/CSA Z412-M00), Toronto, Canada, 2000.

[31] S. C. Bakhtiar, S. Sapur, and P. S. Deb, "Forward head posture is the cause of "Straight Spine Syndrome" in many professionals," Indian Journal of Occupational and Environmental Medicine, vol. 4, no. 3, pp. 122-124, 2000.

[32] D. A. W. M. van der Windt, E. Thomas, D. P. Pope et al., "Occupational risk factors for shoulder pain: a systematic review," Occupational and Environmental Medicine, vol. 57, no. 7, pp. 433-442, 2000.

[33] S. Torp, T. Riise, and B. E. Moen, "The impact of psychosocial work factors on musculoskeletal pain: a prospective study," Journal of Occupational and Environmental Medicine, vol. 43, no. 2, pp. 120-126, 2001.

[34] National Research Council and the Institute of Medicine, Musculoskeletal Disorders and the Workplace, National Academy Press, Washington, DC, USA, 2001.

[35] American National Standards/Human Factors Engineering Society, Human Factors Engineering of Computer Workstations, (BSR/HFES100, HFES. ANSI/HFES committee), Marcel Dekker, New York, NY, USA, 2002.

[36] R. Kadefors and T. Läubli, "Muscular disorders in computer users: introduction," International Journal of Industrial Ergonomics, vol. 30, no. 4-5, pp. 203-210, 2002.

[37] P. W. Buckle and J. Jason Devereux, "The nature of workrelated neck and upper limb musculoskeletal disorders," Applied Ergonomics, vol. 33, no. 3, pp. 207-217, 2002. 
[38] P. M. Bongers, H. C. de Vet, and B. M. Blotter, "Repetitive strain injury (RSI): occurrence, etiology, therapy and prevention," Nederlands Tijdschrift voor Geneeskunde, vol. 146, no. 42, pp. 1971-1976, 2002.

[39] L. Ortiz-Hernández, S. Tamez-González, S. Martínez-Alcántara, and I. Méndez-Ramírez, "Computer use increases the risk of musculoskeletal disorders among newspaper office workers," Archives of Medical Research, vol. 34, no. 4, pp. 331-342, 2003.

[40] T. Korhonen, R. Ketola, R. Toivonen, R. Luukkonen, M. Häkkänen, and E. Viikari-Juntura, "Work related and individual predictors for incident neck pain among office employees working with video display units," Occupational and Environmental Medicine, vol. 60, no. 7, pp. 475-482, 2003.

[41] C. Jensen, "Development of neck and hand-wrist symptoms in relation to duration of computer use at work," Scandinavian Journal of Work, Environment and Health, vol. 29, no. 3, pp. 197205, 2003.

[42] Z. Ming, M. Närhi, and J. Siivola, "Neck and shoulder pain related to computer use," Pathophysiology, vol. 11, no. 1, pp. 5156, 2004.

[43] H. Yang and K. Chandler, "Computer's impact on leisure," in Encyclopedia of Recreation and Leisure in America, G. S. Cross, Ed., vol. 1, pp. 231-239, Charles Scribner's Sons, 2004.

[44] Ministry of Labor (MOL), Computer ergonomics: work station layout lighting, Professional and MOL Queen's printer Ontario, Canada, pp 1-12, 2004.

[45] B. Piccoli, G. Soci, P. L. Zambelli, and D. Pisaniello, "Photometry in the Workplace: the rationale for a new method," Annals of Occupational Hygiene, vol. 48, no. 1, pp. 29-38, 2004.

[46] G. D. Huang and M. Feuerstein, "Identifying work organization targets for a work related musculoskeletal symptoms prevention programme," Journal of Occupational Rehabilitation, vol. 14, no. 1, pp. 13-30, 2004.

[47] B. Juul-Kristensen, K. Søgaard, J. Strøyer, and C. Jensen, “Computer users' risk factors for developing shoulder, elbow and back symptoms," Scandinavian Journal of Work, Environment and Health, vol. 30, no. 5, pp. 390-398, 2004.

[48] K. B. Veiersted, T. Nordberg, and M. Waersed, "A critical review of evidence for a causal relationship between computer work and musculoskeletal disorders with physical findings of the neck and upper extremity," in Den Videnskabelige Komite Dansk Selkab for Arbejdsog Miljomedicin, pp. 1-53, 2006.

[49] E. M. Meijer, J. K. Sluiter, and M. H. W. Frings-Dresen, "What is known about temperature and complaints in the upper extremity? A systematic review in the VDU work environment," International Archives of Occupational and Environmental Health, vol. 79, no. 6, pp. 445-452, 2006.

[50] D. Bhanderi, S. Choudhary, V. Dashi, and L. Pormar, "A study of Occurrence of musculoskeletal discomfort in computer operators," Indian Journal of Community Medicine, vol. 33, no. 1, pp. 65-66, 2008.

[51] Z. Yan, L. Hu, H. Chen, and F. Lu, "Computer vision syndrome: a widely spreading but largely unknown epidemic among computer users," Computers in Human Behavior, vol. 24, no. 5, pp. 2026-2042, 2008.

[52] A. Ellahi, M. S. Khalil, and F. Akram, "Computer users at risk: health disorders associated with prolonged computer use," Journal of Business Management and Economics, vol. 2, no. 4, pp. 171-182, 2011.
[53] S. R. Shrivastava and P. S. Bobhate, "Computer related health problems among software professionals in Mumbai: a crosssectional study," International Journal of Health and Allied Sciences, vol. 1, no. 2, pp. 74-78, 2012.

[54] E. B. Chapnik and C. M. Gross, "Evaluation, office improvements can reduce VDT operator problems," Occupational Health and Safety, vol. 56, no. 7, pp. 34-37, 1987.

[55] T. Laubli, W. Hunting, and E. Grandjean, "Visual impairments in VDU operators related to environmental conditions," in Ergonomic Aspects of Visual Display Terminals, E. Grandjean and E. Vigliant, Eds., pp. 85-94, Taylor \& Francis, London, UK, 1980.

[56] M. Miyao, S. S. Hacisalihzade, J. S. Allen, and L. W. Stark, "Effects of VDT resolution on visual fatigue and readability: an eye movement approach," Ergonomics, vol. 32, no. 6, pp. 603614, 1989.

[57] S. Kanaya, "Vision and visual environment for VDT work," Ergonomics, vol. 33, no. 6, pp. 775-785, 1990.

[58] W. Hanne and H. Brewitt, "Changes in visual function following work at video display terminals," Ophthalmologe, vol. 91, no. 1, pp. 107-112, 1994.

[59] W. Jaschinski-Kruza, "Eyestrain in VDU users: Viewing distance and the resting position of ocular muscles," Human Factors, vol. 33, no. 1, pp. 69-83, 1991.

[60] P. T. Yeow and S. P. Taylor, "Effects of long-term visual display terminal usage on visual functions," Optometry and Vision Science, vol. 68, no. 12, pp. 930-941, 1991.

[61] K. Nakamori, T. Nakajima, M. Odaware, T. Yoshida, and K. Tsubota, "Dry eyes in VDT work," Investigative Ophthalmology \& Visual Science, vol. 34, article 1471, 1993.

[62] K. Nakamori, M. Odaware, T. Nakajima et al., "Dry eye and ocular fatigue in VDT work," Investigative Ophthalmology \& Visual Science, vol. 35, p. 1694, 1994.

[63] I. Lie and R. G. Watten, "VDT work, oculomotor strain, and subjective complaints: an experimental and clinical study," Ergonomics, vol. 37, no. 8, pp. 1419-1433, 1994.

[64] U. O. Bergqvist and B. G. Knave, "Eye discomfort and work with visual display terminals," Scandinavian Journal of Work, Environment and Health, vol. 20, no. 1, pp. 27-33, 1994.

[65] R. G. Watten, I. Lie, and O. Birketvedt, “The influence of longterm visual near-work on accommodation and vergence: a field study," Journal of Human Ergology, vol. 23, no. 1, pp. 27-39, 1994.

[66] L. Toppel and M. Neuber, "Evaluation of refractive values in patients working for several years at video display terminals. A long-term study, Der Ophthalmologe : Zeitschrift der Deutschen Ophthalmologischen Gesellschaft, vol. 91, no. 1, pp. 103-106, 1994.

[67] T. Hikichi, A. Yoshida, Y. Fukui et al., "Prevalence of dry eye in Japanese eye centers," Graefe's Archive for Clinical and Experimental Ophthalmology, vol. 233, no. 9, pp. 555-558, 1995.

[68] B. L. Cole, J. D. Maddocks, and K. Sharpe, "Effect of VDUs on the eyes: report of a 6-year epidemiological study," Optometry \& Vision Science, vol. 73, no. 8, pp. 512-528, 1996.

[69] B. Piccoli, M. Braga, P. L. Zambelli, and A. Bergamaschi, "Viewing distance variation and related ophthalmological changes in office activities with and without VDUs," Ergonomics, vol. 39, no. 5, pp. 719-728, 1996.

[70] C. Rechichi, C. A. de Mojà, and L. Scullica, "Psychology of computer use-36. Visual discomfort and different types of work at videodisplay terminals," Perceptual and Motor Skills, vol. 84, no. 3, pp. 935-938, 1996. 
[71] D. O. Mutti and K. Zadnik, "Is computer use a risk factor for myopia?" Journal of the American Optometric Association, vol. 67, no. 9, pp. 521-530, 1996.

[72] W. D. Thomson, "Eye problems and visual display terminals: the facts and the fallacies," Ophthalmic and Physiological Optics, vol. 18, no. 2, pp. 111-119, 1998.

[73] H. Nakaishi and Y. Yamada, "Abnormal tear dynamics and symptoms of eyestrain in operators of visual display terminals," Occupational and Environmental Medicine, vol. 56, no. 1, pp. 69, 1999.

[74] F. Mocci, A. Serra, and G. A. Corrias, "Psychological factors and visual fatigue in working with video display terminals," Occupational and Environmental Medicine, vol. 58, no. 4, pp. 267-271, 2001.

[75] P. H. Travers and B. Stanton, "Office workers and video display terminals: physical, psychological and ergonomic factors," AAOHN Journal, vol. 50, no. 11, pp. 489-493, 2002.

[76] C. Blehm, S. Vishnu, A. Khattak, S. Mitra, and R. W. Yee, "Computer vision syndrome: a review," Survey of Ophthalmology, vol. 50, no. 3, pp. 253-262, 2005.

[77] V. Woods, "Musculoskeletal disorders and visual strain in intensive data processing workers," Occupational Medicine, vol. 55, no. 2, pp. 121-127, 2005.

[78] M. Uchino, D. A. Schaumberg, M. Dogru et al., "Prevalence of dry eye disease among Japanese visual display terminal users," Ophthalmology, vol. 115, no. 11, pp. 1982-1988, 2008.

[79] C. Fenga, P. Aragona, A. Cacciola et al., "Meibomian gland dysfunction and ocular discomfort in video display terminal workers," Eye, vol. 22, no. 1, pp. 91-95, 2008.

[80] S. Nakamora, S. Kinoshita, N. Yokio et al., "Lacrimal Hypofunction as a new mechanism of dry eye in visual display terminal users," PLoS ONE, vol. 5, no. 6, Article ID e11119, 2010.

[81] T. Kojima, O. M. A. Ibrahim, T. Wakamatsu et al., “The impact of contact lens wear and visual display terminal work on ocular surface and tear functions in office workers," The American Journal of Ophthalmology, vol. 152, no. 6, pp. 933-940, 2011.

[82] C. Ünlü, E. Güney, B. I. S. Akçay, G. Akçali, G. Erdoğan, and H. Bayramlar, "Comparison of ocular-surface disease index questionnaire, tearfilm break-up time, and Schirmer tests for the evaluation of the tearfilm in computer users with and without dry-eye symptomatology," Clinical Ophthalmology, vol. 6, no. 1, pp. 1303-1306, 2012.

[83] M. Uchino, N. Yokoi, Y. Uchino et al., "Prevalence of dry eye disease and its risk factor in visual display terminal users. The Osaka Study," American Journal of Ophthalmology, vol. 156, no. 4, pp. 759-766, 2013.

[84] M. Uchino, N. Yokoi, Y. Uchino et al., "Dry eye disease and work productivity loss in visual display users: the Osaka Study," American Journal of Ophthalmology, vol. 157, no. 2, pp. 294-300, 2014.

[85] ISG, ISO/TC 205/WG7 N4, Building Environment Design. Design Criteria for Visual Comfort, International Standards Organization, Geneva, Switzerland, 1997.

[86] I. Knez and C. Kers, "Effects of indoor lighting, gender, and age on mood and cognitive performance," Environment and Behavior, vol. 32, no. 6, pp. 817-831, 2000.

[87] B. M. Blatter and P. M. Bongers, "Duration of computer use and mouse use in relation to musculoskeletal disorders of neck or upper limb," International Journal of Industrial Ergonomics, vol. 30, no. 4-5, pp. 295-306, 2002.
[88] B. Larsson, K. Søgaard, and L. Rosendal, "Work related neckshoulder pain: a review on magnitude, risk factors, biochemical characteristics, clinical picture and preventive interventions," Best Practice and Research: Clinical Rheumatology, vol. 21, no. 3, pp. 447-463, 2007.

[89] "Keys to Health Computing-Health problems of VDT work," http://www.asfcme.org/health/keys02.htm. 


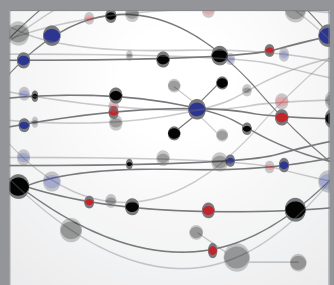

The Scientific World Journal
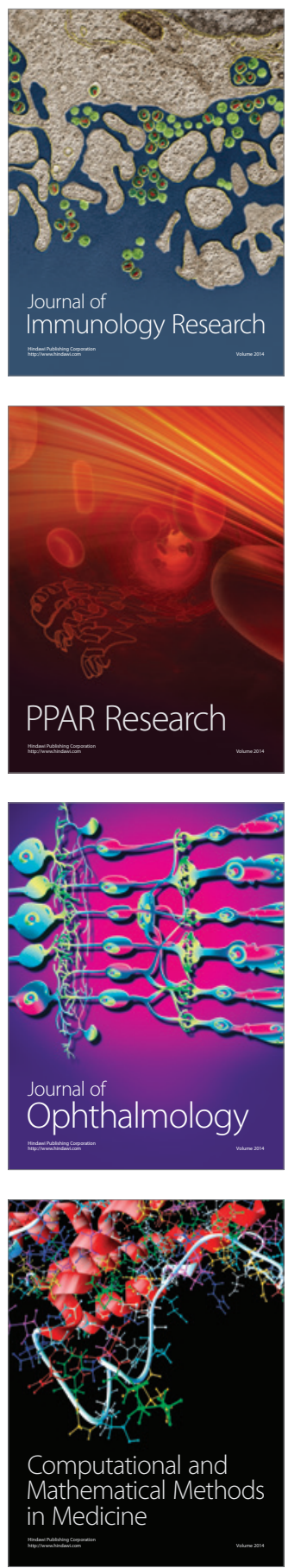

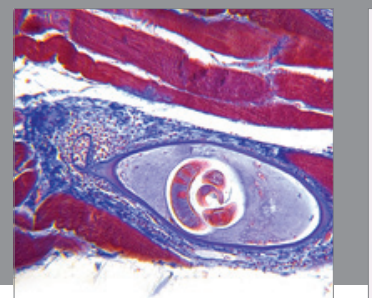

Gastroenterology

Research and Practice
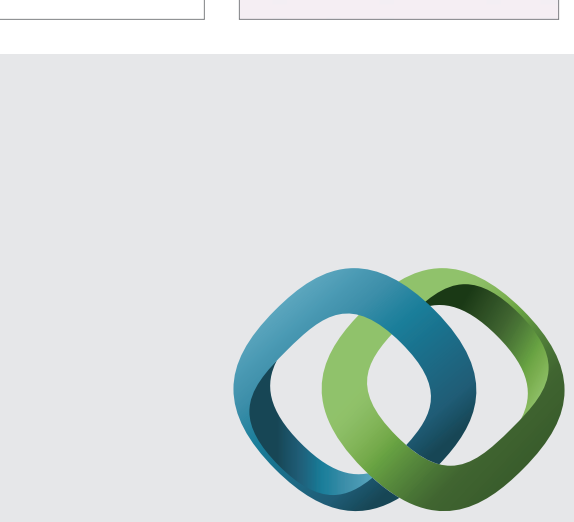

\section{Hindawi}

Submit your manuscripts at

http://www.hindawi.com
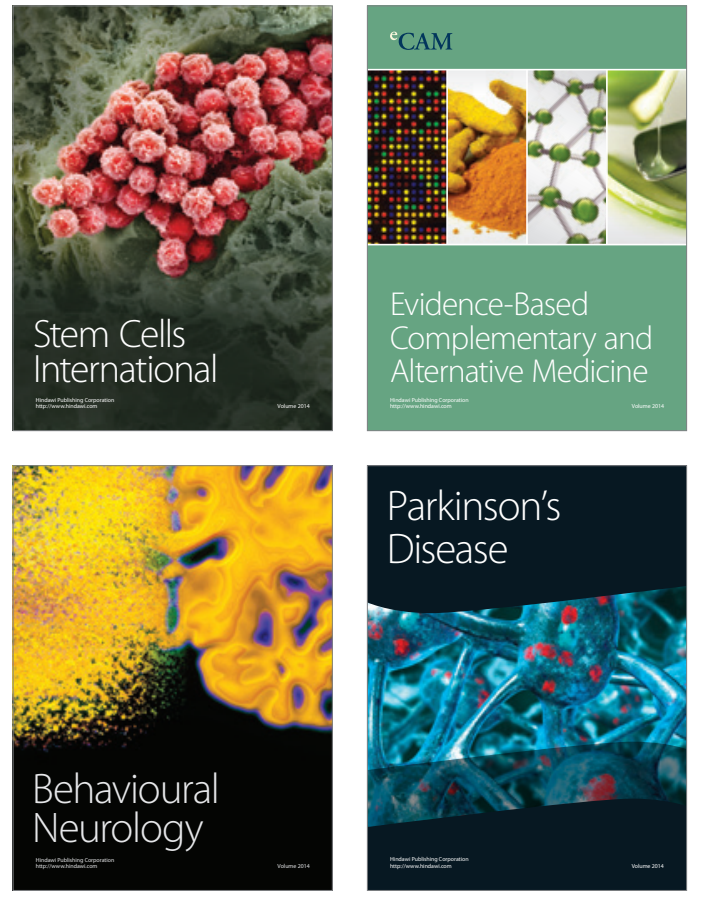
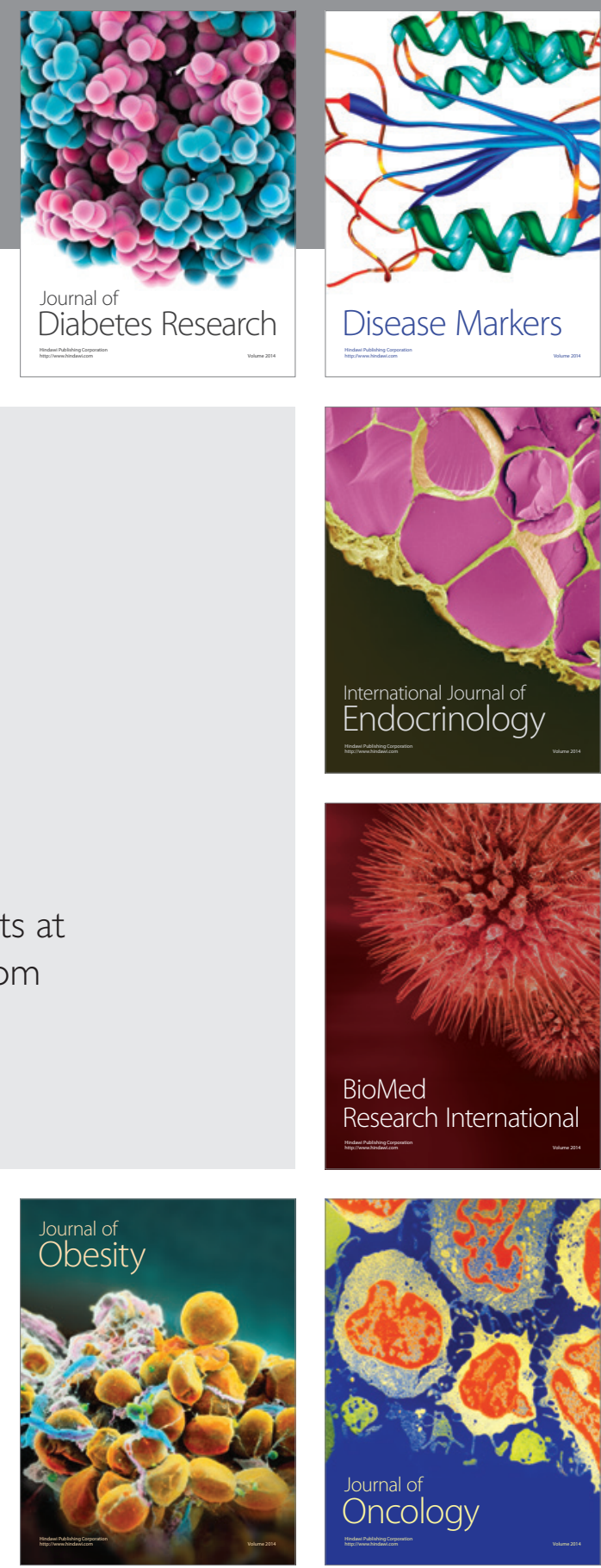

Disease Markers
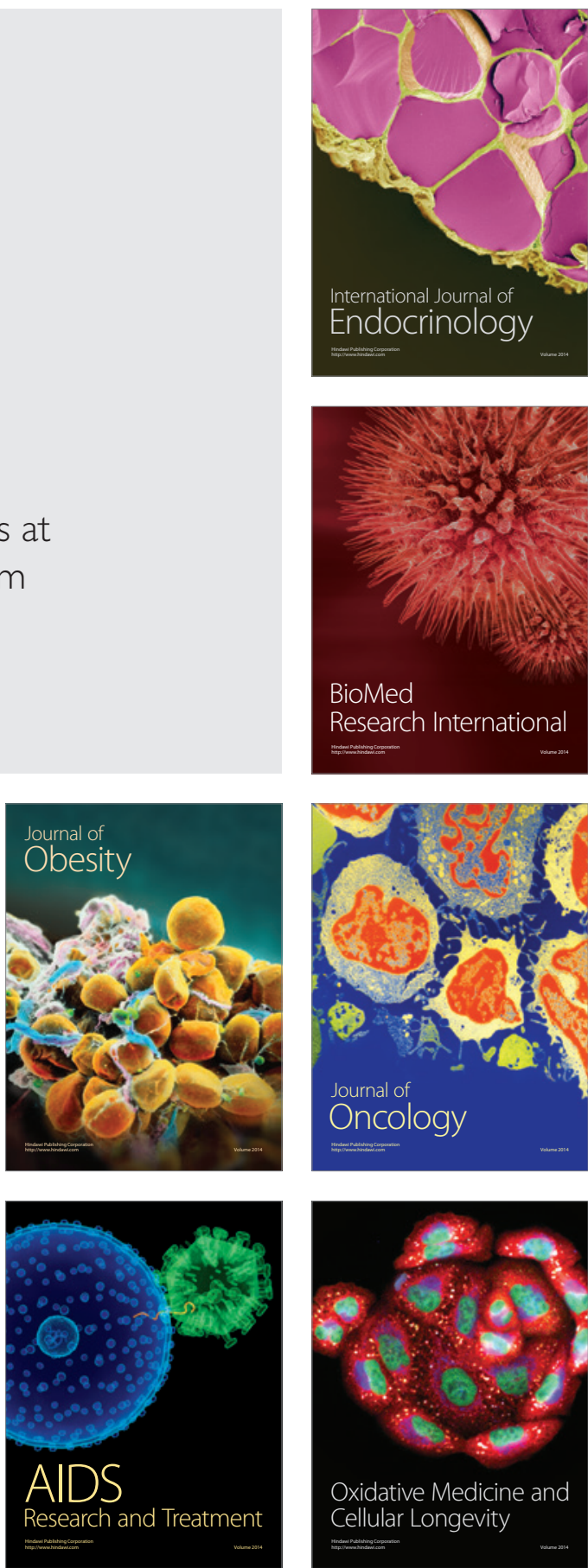